\title{
Role of cement paste composition on the self induced stress in early-age mortars: Application of the Cosserat size number
}

\author{
Hamidréza Ramézani ${ }^{\mathrm{a}, *}$, Pierre Mounanga ${ }^{\mathrm{b}, 1}$, Jena Jeong ${ }^{\mathrm{c}, *}$, Marwen Bouasker ${ }^{\mathrm{a}, 2}$ \\ ${ }^{a}$ CRMD, CNRS FRE 3520-Research Center on Divided Materials, École Polytechnique de l'Université d'Orléans, 8 rue Léonrad de Vinci, 45072 Orléans, France

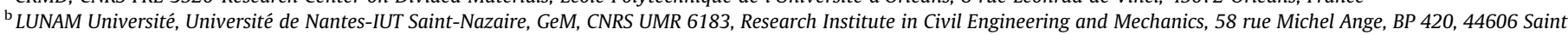 \\ Nazaire cedex, France \\ ${ }^{c}$ ESTP/IRC-École Spéciale des Travaux Publics, du Bâtiment et de l'industrie (ESTP), 28 Avenue du Président Wilson, 94234 Cachan, France
}

\begin{abstract}
The self-induced stress in mortars caused by autogenous shrinkage phenomenon at very early age has been investigated by taking advantage of the experimental results and application of hygro-Cosserat theory. Three cement matrices, prepared with three different types of cement, have been considered to analyze the role of cement paste composition on the development of these initial stresses surrounding the aggregates. The induced bulk deformations around the aggregates have been thereafter scrutinized by means of hygro-Cosserat elasticity taking into account the size effect in an explicit manner and a newly defined parameter called Cosserat size effect number (CS). By taking advantage of the autogenous shrinkage experiments on the cement pastes, the parallel time-dependent finite element analyses have been achieved considering the aggregate-to-cement ratio. The aforementioned parameters are put into practice to create an analytical pseudo-stochastic geometry using a spherical-packing algorithm. The numerical outcomes were analyzed and compared to the experimental outcomes coming from the Scanning Electronic Microscopy observations at $48 \mathrm{~h}$ after hydration.
\end{abstract}

\section{Problem statement and scientific backbone}

\subsection{Physico-chemical approach: basic mechanisms of autogenous shrinkage}

The physico-chemical and micro-structural evolution of earlyage cementitious matrices are characterized by significant volume variations. These volume changes are related to the chemical reactions between cement and water. They are due to Le Chatelier contraction $^{3}$ and to the exothermic hydration reactions that lead to the thermally-induced material deformations. The progressive hardening of the cement-based matrix restricts the development of volume variations, without being able to completely prevent it. In high-performance cementitious matrices with low initial water

\footnotetext{
* Corresponding authors. Tel.: +33 238 257879; fax: +33 238255376 (H. Ramézani), tel.: +33149 082303; fax:+33145476039 (J. Jeong).

E-mail addresses: hamidreza.ramezani@univ-orleans.fr, hamidreza.ramezzani@gmail.com (H. Ramézani), pierre.mounanga@univ-nantes.fr (P. Mounanga), jeong@profs.estp.fr, jena.jeong@gmail.com (J. Jeong), marwen.bouasker@univ-orleans.fr (M. Bouasker).

1 Tel.: +33240 178189; fax: +33240178160.

2 Tel.: +33238 492771; fax: +33238255376

3 Le Chatelier contraction corresponds to the difference in absolute density between the hydration reaction products (hydrates and portlandite) and reactants (cement and water).
}

content, the hydration also causes water desaturation of the capillary pore network. This creates an internal capillary depression, resulting in a macroscopic contraction of the mineral skeleton. These autogenous deformations develop even when the material is protected from drying excluding the external loads.

The early-age autogenous shrinkage of cement matrices, if restrained, may cause damage to the material: in fact, at early-age, the driving mechanisms involved in the evolution of shrinkage (hydration and Le Chatelier contraction) grow quickly. This fast change, coupled with a significant increase in stiffness of the material due to its hardening, induces the development of internal stresses, when the material is not free to deform.

In concrete, this situation particularly occurs around the aggregates: in this zone, the hindering effect pertaining to the cement paste deformations gives rise to the self-induced stresses. When they are high enough, they sustain micro-cracking of the cement matrix. This risk is particularly high at early-age, during the first days of hydration, when the tensile strength of the material is still weak.

\subsection{Effects of cement paste composition}

All cements do not behave similarly in front of the risk of earlyage micro-cracking. According to their chemical compositions and physico-chemical properties (particle size distribution and specific surface area), they can exhibit higher or lower autogenous 


\section{Nomenclature}

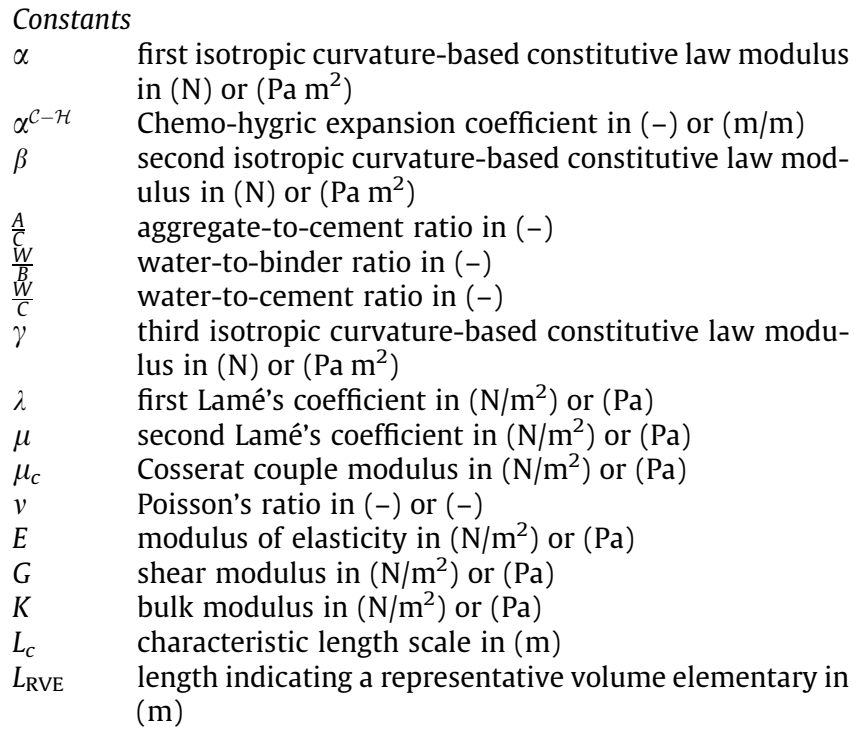

$\alpha \quad$ first isotropic curvature-based constitutive law modulus in $(\mathrm{N})$ or $\left(\mathrm{Pa} \mathrm{m}^{2}\right)$

$\alpha^{\mathcal{C}-\mathcal{H}} \quad$ Chemo-hygric expansion coefficient in $(-)$ or $(\mathrm{m} / \mathrm{m})$

$\beta \quad$ second isotropic curvature-based constitutive law modulus in $(\mathrm{N})$ or $\left(\mathrm{Pa} \mathrm{m}^{2}\right)$

$\frac{A}{C} \quad$ aggregate-to-cement ratio in (-)

$\frac{W}{B} \quad$ water-to-binder ratio in (-)

$\frac{W}{C} \quad$ water-to-cement ratio in $(-)$

$\gamma$ third isotropic curvature-based constitutive law modulus in $(\mathrm{N})$ or $\left(\mathrm{Pa} \mathrm{m}^{2}\right)$

$\lambda \quad$ first Lamé's coefficient in $\left(\mathrm{N} / \mathrm{m}^{2}\right)$ or $(\mathrm{Pa})$

$\mu \quad$ second Lamé's coefficient in $\left(\mathrm{N} / \mathrm{m}^{2}\right)$ or $(\mathrm{Pa})$

$\mu_{c} \quad$ Cosserat couple modulus in $\left(\mathrm{N} / \mathrm{m}^{2}\right)$ or $(\mathrm{Pa})$

$v \quad$ Poisson's ratio in $(-)$ or $(-)$

E modulus of elasticity in $\left(\mathrm{N} / \mathrm{m}^{2}\right)$ or $(\mathrm{Pa})$

$G \quad$ shear modulus in $\left(\mathrm{N} / \mathrm{m}^{2}\right)$ or $(\mathrm{Pa})$

$K \quad$ bulk modulus in $\left(\mathrm{N} / \mathrm{m}^{2}\right)$ or $(\mathrm{Pa})$

$L_{c} \quad$ characteristic length scale in $(\mathrm{m})$

$L_{\mathrm{RVE}} \quad$ length indicating a representative volume elementary in (m)

Third-rank tensor quantities

$e \quad$ third-rank permutation tensor or Levi-Civita tensor in $(-)$

\author{
Sets \\ $\mathbb{M}^{3 \times 3}$ or $\mathbb{R}^{3} \times \mathbb{R}^{3}$ set of real $3 \times 3$ s-rank tensors \\ $\mathbb{N} \quad$ Natural set \\ $\mathbb{R}^{3} \quad$ first-rank Euclidean space \\ $\mathbb{R}^{27}$ or $\mathbb{R}^{3} \times \mathbb{R}^{3} \times \mathbb{R}^{3}$ third-rank Euclidean space
}

Second-rank tensor quantities

$\bar{\epsilon}^{\mathcal{M}} \quad$ mechanical first Cosserat stretch tensor in $(\mathrm{m} / \mathrm{m})$ or $(-)$

$\bar{A} \quad$ dual tensor of micro-rotation in (rad)

$\bar{k}^{\mathcal{M}}$ mechanical curvature tensor or mechanical wryness tensor in $(\mathrm{rad} / \mathrm{m})$

$\epsilon:=\operatorname{sym} \nabla \otimes u=\operatorname{sym} \nabla u$ total infinitesimal strain in (-)

$\epsilon^{\mathcal{C}-\mathcal{H}} \quad$ infinitesimal chemo-hygric strain in (-)

$\widehat{A} \quad$ rotation matrix

$\widehat{W} \quad$ skew-symmetric matrix dealing with the pure conformal deformation

$1 \quad$ identity tensor in (-)

$\nabla \otimes \phi \quad$ gradient of micro-rotation vector in accordance with the Einstein's summation convention in $(1 / \mathrm{m})$ or $(\mathrm{rad} / \mathrm{m})$ $\nabla \otimes u \quad$ gradient of displacement vector in accordance with the Einstein's summation convention in $(-)$ or $(\mathrm{m} / \mathrm{m})$

$\nabla \phi:=(\nabla \otimes \phi)^{T}=\phi_{i, j} \hat{e}_{i} \otimes \hat{e}_{j}$ micro-rotation gradient in $(1 / \mathrm{m})$ or $(\mathrm{rad} / \mathrm{m})$

$\nabla u:=(\nabla \otimes \phi)^{T}=\phi_{i, j} \hat{e}_{i} \otimes \hat{e}_{j}$ displacement gradient in (-) or $(\mathrm{m} /$ $\mathrm{m})$

$\bar{\varepsilon} \quad$ Cosserat first stretch tensor in $(-)$ or $(\mathrm{m} / \mathrm{m})$

$\sigma \quad$ asymmetric stress tensor in $\left(\mathrm{N} / \mathrm{m}^{2}\right)$ or $(\mathrm{Pa})$

$\mathrm{F}^{\mathcal{C}}$ decomposed gradient deformation tensor indicating chemical-based stretch in (-)

$\mathrm{F}^{\mathcal{H}}$ decomposed gradient deformation tensor indicating

hygric stretch in (-)

${ }_{\mathrm{F}} \mathcal{M}_{e} \quad$ decomposed gradient deformation tensor indicating elastic stretch in (-)

$\mathrm{F}^{\mathcal{M}_{p}} \quad$ decomposed gradient deformation tensor indicating plastic stretch in $(-)$

$\mathrm{F}^{\mathcal{T}} \quad$ decomposed gradient deformation tensor indicating thermal stretch in (-)

$F \quad$ gradient deformation tensor in $(-)$ or $(\mathrm{m} / \mathrm{m})$

$k \quad$ linear Cosserat curvature or wryness tensor in $(\mathrm{rad} / \mathrm{m})$

$m \quad$ stress moment tensor in $\left(\mathrm{N} \mathrm{m} / \mathrm{m}^{2}\right)$ or $(\mathrm{Pa} \mathrm{m})$

$X$ and $Y$ arbitrary second-rank tensors

$\epsilon^{\mathcal{C}} \quad$ chemical-based strain in (-)

$\epsilon^{\mathcal{H}} \quad$ moisture-induced strain or hygric strain in (-)

$\epsilon^{\mathcal{M}_{e}} \quad$ elastic strain in (-)

$\epsilon^{\mathcal{M}_{p}} \quad$ plastic strain in (-)

$\epsilon^{\mathcal{T}} \quad$ thermal strain in (-)

Scalar quantities

$\Delta \Pi \quad$ relative humidity change in (-) or $\left(\mathrm{m}^{3} / \mathrm{m}^{3}\right)$

$\hat{p} \quad$ dilatation

$\Pi \quad$ relative humidity in (-) or $\left(\mathrm{m}^{3} / \mathrm{m}^{3}\right)$

$T \quad$ temperature in $\left({ }^{\circ} \mathrm{C}\right)$

$W_{\text {curv }}(k)$ curvature energy density in $\left(\mathrm{J} / \mathrm{m}^{3}\right)$

CS Cosserat size effect number in $(\mathrm{m} / \mathrm{m})$

Vector quantities

$\hat{b} \quad$ translation vector

$\phi \quad$ micro-rotation vector in (rad)

$a, b$ and $x$ arbitrary vectors

$f \quad$ vector indicating body force in $\left(\mathrm{N} / \mathrm{m}^{3}\right)$

$u \quad$ displacement vector in ( $\mathrm{m})$

$x \quad$ position vector in $(\mathrm{m})$ shrinkage and ability to relax stress and mechanical performances. Despite the large number of studies carried out in this field, it is not easy to reach rational conclusions about the relationships between the free or restrained autogenous shrinkage and the chemical composition of the considered cement. Indeed, the measurement of early-age autogenous shrinkage remains an extremely difficult task. A recent study demonstrated that, even with sophisticated equipments, it is difficult to obtain a reproducible measurement of early-age autogenous shrinkage [1]. Moreover, the issue of the initialization of self-desiccation deformations from a reference time or so-called time zero is still an open problem in the cement and concrete society.

Several questions still remain unanswered, concerning the influence of supplementary cementitious materials on the autogenous shrinkage of cement-based matrices. It was observed that the blast furnace slag (BFS) cements showed higher free autogenous shrinkage than that of Portland cement [2-4]. This difference is generally explained by a higher chemical shrinkage and a finer porosity of BFS cement matrices, which cause more intense capillary pressure [5]. The previous studies have also substantiated that the early-age deformations of BFS cement concrete were characterized by an initial expansion phase [6,7]. This expansion is usually attributed to the formation of crystalline hydration products, which generates pressure on the pore walls resulting in swelling of the mineral skeleton. Other authors did not observe such phenomena $[8-10,4]$, even when the autogenous deformations were monitored from the very first hours after the mixing action.

The partial substitution of Portland cement with limestone filler induces an increase of early-age chemical shrinkage expressed in $\mathrm{mm}^{3}$ per gram of Portland cement [11]. This increase is caused by the accelerating effect of limestone filler on Portland cement hydration [12,11,13]. Itim et al. [14] also observed that the early-age autogenous shrinkage of super-plasticized mortars increased by $10 \%$ when the cement content was changed from $15 \%$ 
to $25 \%$ of limestone powder. Furthermore, Mounanga et al. [15] found out that the presence of limestone filler in the cement paste could provide a decrease of autogenous shrinkage expressed in $\mathrm{mm}^{3}$ per gram of binder. This phenomenon was attributed to the dilution effect of limestone filler leading to an increase of the water-to-clinker ratio and a consecutive diminution of the capillary pressure effects. The fineness of cement also plays an essential role, a finer cement inducing a higher autogenous shrinkage rate. Indeed, the finer cements hydrate faster. At a given time, the chemical shrinkage develops more rapidly for the finer cements rather than coarser cements. It is well worth noting that the chemical shrinkage is proportional to the degree of hydration $[16,17]$. The reduction of relative humidity, i.e. $\Pi$, due to the self-desiccation, is also accelerated and results in higher values of the capillary pressure. Therefore, it sustains greater autogenous shrinkage deformations [18-20].

\subsection{Effects of aggregates}

Historically, Pickett [21] was first to propose the analytical description of the influence of aggregates on concrete shrinkage. This analysis stems from the theory of elasticity. The aforementioned analytical description has undergone several improvements and modifications. These improvement take into account the deformation of aggregates and the elastic properties of various phases of the material, e.g. hydrated cement paste, anhydrous cement grains and aggregate [22-24]. They involve also the presence of an interfacial transition zone (ITZ) between aggregates and cement paste. More recently, some models based on the multi-scale approaches have been developed to simulate more precisely the shrinkage mechanisms at the microscopic and nanometric scales [25-28]. In addition to the above-mentioned parameters, these models take into account the effects of cement type, water-to-cement $\left(\frac{W}{C}\right)$ ratio, and aging of cement paste.

However, these models do not allow describing all of the hygromechanical interactions that may exist between the aggregates and cement matrix. Indeed, from a mechanical point of view, the restraining of the matrix deformation causes the internal stresses that can conduct radial micro-crackings and debonding of the cement paste from the aggregates phenomena [29-33].

The 2D mathematical analysis suggested by Hsu [29] and Goltermann [34,35] on a two-phase material, and followed by the analysis of Garboczi [36] on a three phase material, showed that the micro-cracking of the cement paste depends on the inter-granular distance and the behavior of each phase (expansion or contraction). Hsu stated that the compressive and tensile stresses would be seen at the interface between paste and aggregate and in the cement paste matrix [29]. The stress distribution depends on the concentration of aggregates. When the tensile stresses in the radial direction get greater than the tangential direction, there is a separation between the aggregate and the cement paste. ${ }^{4}$ Otherwise, the cracking of the cement paste develops radially from the aggregates $[29,36]$. More sophisticated 2D multi-scale models have been recently proposed considering aggregates with more realistic shapes [37] and moisture transfer between the interface zone and the bulk of cement paste [38].

\subsection{Paper highlights}

- To complete and improve the analysis of mortar shrinkage phenomenon, the authors propose a multi-scale approach based upon the hygro-Cosserat theory [39] using the conformal energy density [40-45]. To achieve this goal, the Cosserat size

\footnotetext{
${ }^{4}$ It is of great importance to note that the interface strength is neglected.
}

effect number, defined as the ratio between a characteristic length scale $\left(L_{c}\right)$ and a representative volume elementary length of the material, is used $\left(L_{\mathrm{RVE}}\right)$ :

$$
\mathrm{CS}=\frac{L_{c}}{L_{\mathrm{RVE}}}
$$

- The potential effects of the chemical composition of cement on the self-induced stress field at very early-age and subsequent risk of micro-cracking are particularly investigated. The required parameters for the hygro-Cosserat numerical experiments are obtained from the experimental studies using three different types of cement, i.e. CEMI, CEMII and CEMIII,

- The free autogenous shrinkage and dynamic Young's modulus are measured at very early-age on the cement pastes. The scanning electron microscope observations of the ITZ are also performed within the same period of time, to evaluate the relevance of the numerical analysis.

\section{Theoretical and numerical multi-scale approach: hygro- Cosserat theory background}

\subsection{Cosserat theory based on the conformal curvature energy density}

One of the most outstanding features of Cosserat theory [46,47] is that one can involve the size effect in an explicit manner. This issue can be explained by the fact that smaller sample behaves stiffer than larger sample of the same material. Consequently, the parameters of material are no longer material constants but rather depending on the size of specimen. The Cosserat media can be classified as a member of the generalized continuum media (see Appendix A). ${ }^{5}$ In the Cosserat theory which is a sub-group of the generalized continuum family, besides the Lamé's coefficients $(\lambda$ and $\mu$ ), the application of Cosserat theory needs the knowledge of four supplementary varying parameters $\left(\alpha, \beta, \gamma\right.$ and $\left.\mu_{c}\right)$ explicitly related to the size effect. According to the previous studies $[41,42,56,45,57]$, these additional unknown material parameters or so-called material moduli can be determined from the characteristic length scale and the curvature energy density [41-43]. First, let us get started with establishing the coupled kinematical relations for the linear Cosserat models:

$\bar{\varepsilon}^{T}=\nabla u-\bar{A}, \quad$ first Cosserat stretch tensor

$k=\nabla \phi, \quad$ curvature tensor or wryness tensor

where $u \in \mathbb{R}^{3}, \quad \phi:=\operatorname{axl} \bar{A}=-e_{i j k} A_{j k} \hat{e}_{i} \in \mathbb{R}^{3}, \quad \bar{A}:=\operatorname{anti} \phi=-e_{i j k} \phi_{k} \hat{e}_{i}$ $\otimes \hat{e}_{j} \in \mathfrak{s} 0(3) \subset \mathbb{R}^{3} \times \mathbb{R}^{3}, e:=e_{i j k} \hat{e}_{i} \otimes \hat{e}_{j} \otimes \hat{e}_{k} \in \mathbb{R}^{27}$ and $k \in \mathbb{R}^{3} \times \mathbb{R}^{3}$ are the displacement vector, micro-rotation vector, dual tensor of the micro-rotation vector, third-rank permutation tensor or Levi-Civita tensor and curvature tensor or so-called wryness tensor, respectively.

We collect the balance equations excluding the body force and body moment vectors under strong form $[42,56]$, the constitutive laws for the isotropic Cosserat elasticity models:

$\operatorname{Div} \sigma=f, \quad$ balance of linear momentum

$-\operatorname{Div} m=4 \mu_{c} \cdot \operatorname{axl}($ skew $\bar{\varepsilon})$,

balance of angular momentum

\footnotetext{
5 The generalized continuum media include the additional micro-structural state field variables, e.g. micro-dilatation in micro-dilatation theory $[48,49]$ which can be related to the porosity variation into the porous solids $[50,51]$ like cement-based materials, micro-rotation vector in the micro-polar theory [52,53], micro-rotation vector as well as micro-dilatation in the micro-stretch theory [54,55] and microdeformation second-rank tensor in micro-morphic theory [55].
} 


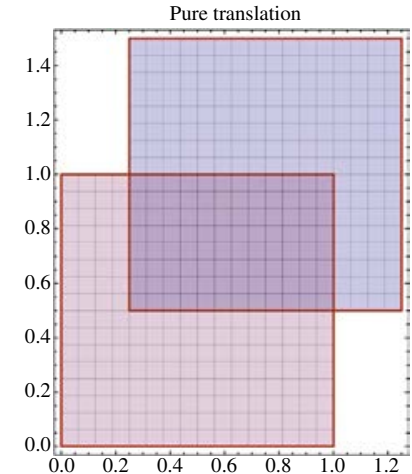

(a)

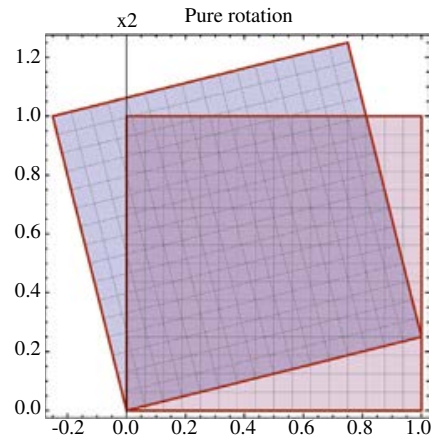

(b)

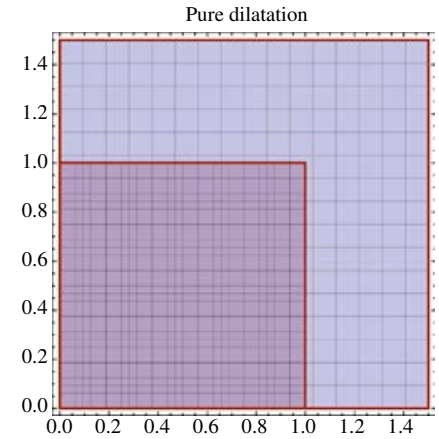

(c)

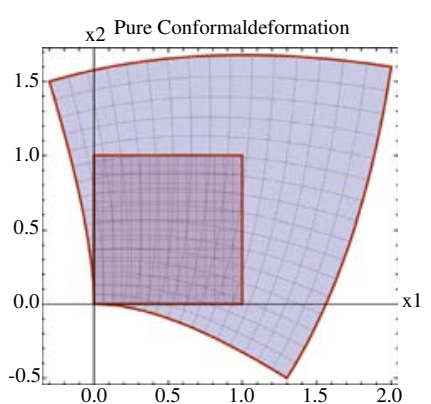

(d)

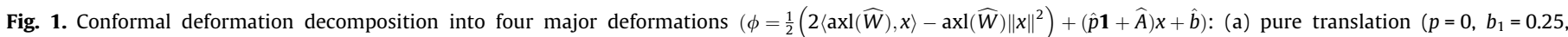

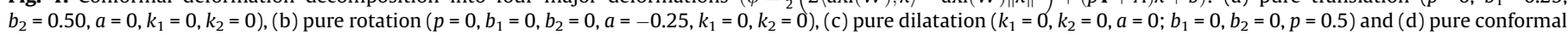
deformation $\left(b_{1}=0, b_{2}=0, k_{1}=0.3, k_{2}=0.5, a=0, p=0\right.$ ), i.e. each part of the solid deforms differently.

$\sigma=2 \mu \cdot \operatorname{sym} \bar{\varepsilon}+2 \mu_{c} \cdot \operatorname{skew} \bar{\varepsilon}+\lambda \cdot \operatorname{tr}[\bar{\varepsilon}] \cdot \mathbf{1}$

$m=\gamma \nabla \phi+\beta(\nabla \phi)^{T}+\alpha \operatorname{tr}[\nabla \phi] \cdot \mathbf{1}$

where $\quad \sigma \in \mathbb{R}^{3} \times \mathbb{R}^{3}, m \in \mathbb{R}^{3} \times \mathbb{R}^{3}, e \in \mathbb{R}^{27}, \quad \mathbf{1}=\delta_{i j} \hat{e}_{i} \otimes \hat{e}_{j} \in \operatorname{ISO}(3)$ $\subset \mathbb{R}^{3} \times \mathbb{R}^{3}, \lambda=\frac{v E}{(1+v)(1-2 v)}, \quad \mu=G=\frac{E}{2(1+v)}, \quad \mu, \alpha, \beta$ and $\gamma$ are nonsymmetric stress tensor, non-symmetric couple stress or stress moment tensor, third-rank Levi-Civita tensor, second-rank isotropic identity tensor, first and second Lamé's coefficients, Cosserat couple modulus and first, second and third material moduli in stress moment-wryness relation $(m-\nabla \phi)$, respectively.

Among recently scrutinized curvature energy densities in $[40,41,45,42,45]$, we utilize the conformal case due to the fact that it is capable of describing the heterogeneous micro-structures, providing the most stable parameters $[45,41]$ in this study.

- Conformal case $[41,42,58,43]$ : This case corresponds to $\alpha=-\frac{\mu L_{c}^{2}}{3}$ and $\beta=\gamma=\frac{\mu L_{c}^{2}}{2}$

$W_{\text {curv }}(\nabla \phi):=\frac{\mu L_{c}^{2}}{2}\|\operatorname{dev} \operatorname{sym} \nabla \phi\|^{2}$

This case is applied in modeling of the micro-structural behavior of cement-based mortar, in which the sand grains and cement matrix provide a non-homogeneous mixture. This non-homogeneous mixture sustains the heterogeneous deformations. These deformations are illustrated in Fig. 1 (see [41]). The pure translation, rotation, dilatation and conformal deformations are displayed in Fig. 1a-d, respectively. In the next subsection, we will numerically evaluate the size effect on the cement-based mortar.

\subsection{Analytical and numerical multi-scale approach based on Cosserat size effect number}

The size effect in the Cosserat theory can be captured by means of the torsion test. This feature has been applied for the multi-scale investigations. The numerical simulation is performed on the rectangular Cosserat bar $(160 \times 40 \times 40[\mathrm{~mm}])$ to reveal the size effect of mortar. The mechanical properties applied for the numerical experiments are presented in Table 1.

The 3D-FEM outcomes of the rectangular Cosserat bar are plotted in a semi-logarithmic diagram using a dimensionless parameter called Cosserat Size effect number (CS) in Fig. 2. In the current paper, $L_{\mathrm{RVE}}$ is assumed to be equal to $100[\mathrm{~mm}]$ for the cementbased mortars (see $[27,39]$ for more details). It is of great importance to note that $L_{\mathrm{RVE}}$ is a material constant. To identify the more relevant scale level for the analysis of micro-crack initiation around the sand grains and through the cement paste matrix, three specific scales are considered and schematized in Fig. 3, corresponding to three distinct zones in Fig. 2:

Table 1

Size-independent and dependent mechanical properties of chosen cement-based mortar applied to the Cosserat conformal curvature energy assumption involving the rectangular Cosserat bar for extracting relevant so-called Cosserat size effect number $\mathrm{CS}=\frac{L_{c}}{L_{\mathrm{RVE}}}$ corresponding to the micro-structure.

\begin{tabular}{ll}
\hline Material constants name & Material constants values \\
\hline Modulus of elasticity, $E$ in $\left(\mathrm{N} / \mathrm{mm}^{2}\right)$ & $30 \times 10^{3}$ \\
Poisson's ratio, $v$ in $(-)$ & 0.28 \\
Cosserat couple modulus, $\mu_{c}$ in $\left(\mathrm{N} / \mathrm{mm}^{2}\right)$ & $\mu_{c}=\mu=\frac{E}{2(1+v)}$ \\
Characteristic length scale, $L_{c}$ in $(\mathrm{mm})$ & $0 \leqslant L_{c} \leqslant 10^{5}$ \\
RVE size, $L_{\mathrm{RVE}}$ in $(\mathrm{mm})$ & $100(\mathrm{see}[27])$ \\
Cosserat Size effect number, $\mathrm{CS}=\frac{L_{c}}{L_{\mathrm{RVE}}}$ in $(-)$ & $10^{-5} \leqslant \mathrm{CS} \leqslant 10^{5}$ \\
\hline
\end{tabular}

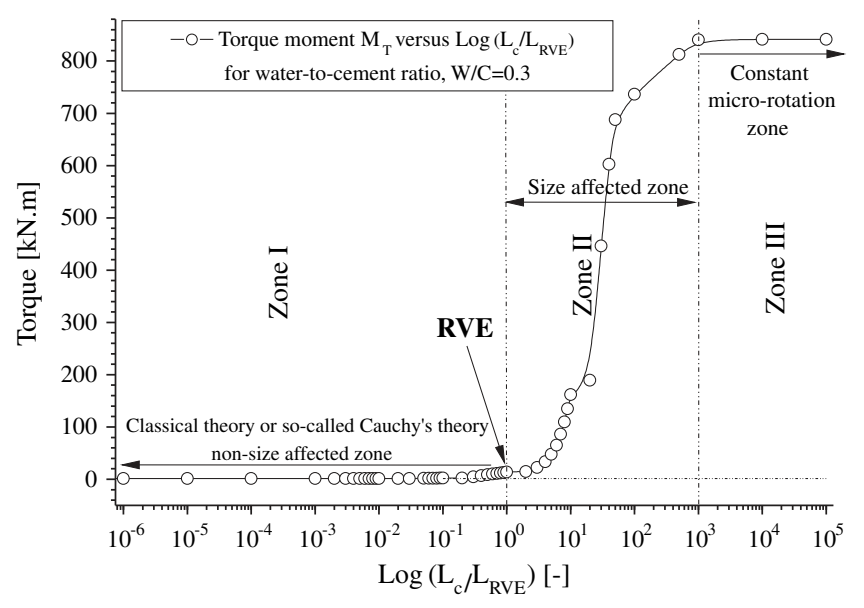

Fig. 2. Relevant size effect with respect to $\log (C S)$ or $\log \left(\frac{L_{c}}{L_{\mathrm{FvE}}}\right)$ via $3 \mathrm{D}-\mathrm{FEM}$ numerical experiments of a rectangular Cosserat bar including $1.2 \mathrm{Mi}$ DOFs, semilogarithmic diagram of torque moment versus $\log (\mathrm{CS})$ or $\log \left(\frac{L_{c}}{L_{\mathrm{RVE}}}\right)$ for conformal case, i.e. $\alpha=-\frac{\mu L_{c}^{2}}{3}, \beta=\gamma=\frac{\mu L_{c}^{2}}{3}$ and $\mu_{c}=\mu=\frac{E}{3(1-2 v)}$ [39]. 


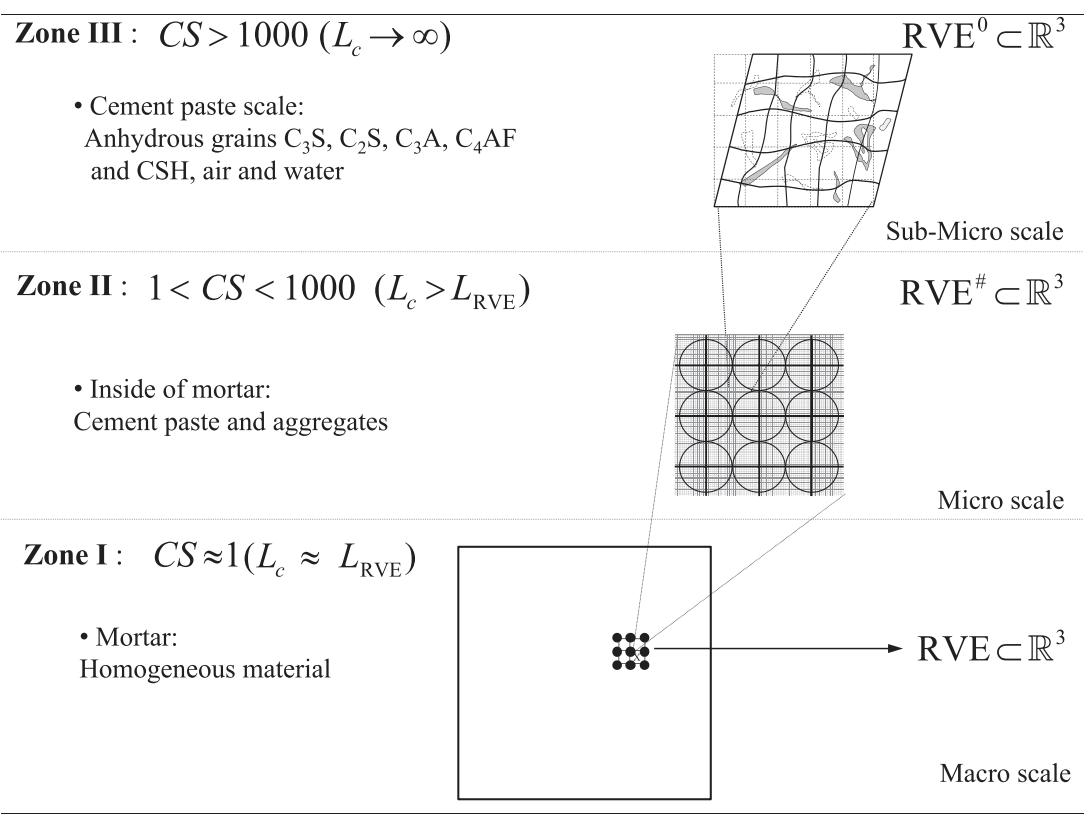

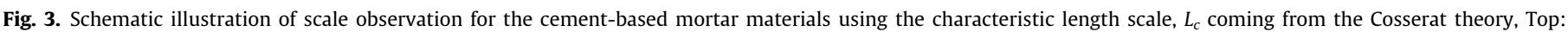

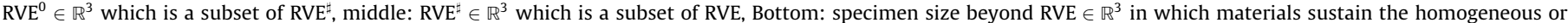
averaged out response [39].

- At macro-scale, which corresponds to Zone I in Figs. 2 and 3 , RVE size, $L_{\mathrm{RVE}}=\operatorname{Size}\left(\operatorname{RVE} \subset \mathbb{R}^{3}\right)$, relative to the characteristic length $L_{c}$ signifies the material itself as a whole and then the stiffness and the strength of the material will not be changed whatever the specimen size. Consequently, the response from $\operatorname{RVE} \subset \mathbb{R}^{3}$ is obviously a homogenized or averaged out value same as those found out in the CauchyBoltzmann's media.

- At micro-scale, which could correspond to Zone II in Figs. 2 and 3 , the material is composed of granular inclusions (sand grains) embedded in a cement-based matrix. This is the appropriate scale to investigate the development of self-induced stress around the sand grains. To characterize this scale, we introduce a new size named as RVE . This indicates that our mortar RVE should be smaller than the classical RVE in Fig. 3.

- At sub-micro scale, $\operatorname{RVE}^{0}$ should be too much smaller than $\mathrm{RVE}^{\sharp}$ and it can be understood in Zone III in Figs. 2 and 3. Different chemical compounds of anhydrous cement, hydrates and water constitute the material. This scale does not make sense for the case in which we concentrate on.

Therefore, our RVE ${ }^{\sharp}$ should be located between Zone I (CauchyBoltzmann's media) and Zone III. The last difficulty is where RVE ${ }^{\sharp}$ is exactly located in Zone II. In this work, we propose to use RVE equal to $100 \times \operatorname{RVE}$ or $C S=\frac{L_{c}}{L_{\text {RVE }}}=100$, where we would expect the stress localizations surrounding the grains through the cement matrix at micro-scale viewpoint.

\subsection{Hygro-Cosserat theory: brief review of the state-of-the-art formulation}

The hygro-Cosserat theory is mainly a multi-disciplinary problem including the size effects in the sense that there are not only the hygric effects stemming from the water action but also their impact on the mechanical response at a specific scale. This is achievable for the infinitesimal deformation measurements under Duhamel-Neumann additive decomposition rule, e.g.
Khoshbakht et al. [59] and Lin et al. [60] for the hygro-mechanical problems. $^{6}$

In the current paper, we take into account only the chemo-hygric strain tensor, $\epsilon^{\mathcal{C}-\mathcal{H}}$ and all the other effects are excluded, i.e. isothermal elastic behavior assumptions:

$\epsilon:=\epsilon^{\mathcal{M}_{e}}+\epsilon^{\mathcal{C}-\mathcal{H}}$

In (6), $\epsilon^{\mathcal{M}_{e}} \in \operatorname{Sym}(3) \subset \mathbb{R}^{3} \times \mathbb{R}^{3}$ and $\epsilon^{\mathcal{C}-\mathcal{H}} \subset \mathbb{R}^{3} \times \mathbb{R}^{3}$ are the elastic mechanical and infinitesimal chemo-hygric strain tensors, respectively. By taking advantage of the above-mentioned deformation measurement decomposition, the following hygroCosserat constitutive laws can be extracted including the linear volumetric or so-called bulk hygric deformation assumption:

\footnotetext{
${ }^{6}$ To establish a unified methodology for treating this problem, it is necessary to get started with the total infinitesimal strain concept. The total strain can be divided into several parts: mechanical strains, thermal strains, moisture-induced strains or so called hygric strains and other strains, e.g. chemical-based strains [61] The total strain additive decomposition or so called Duhamel-Neumann's rule comes from the fact that the strains are infinitesimal and there is neither large deformation nor large rotation measurements for the considered solid. This is often true for the masonry structures and cement pastes. In our case, we expect the infinitesimal strains due to the small amount of deformations. Otherwise, we must decompose the gradient deformation tensor into the elastic, plastic, thermal and hygric parts

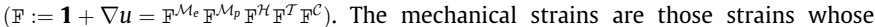
effects can be measured by forces and/or moments. Indeed, they deal with the only the mechanical points of view. The thermal and moisture-induced strains handle the hindered or preventing effects based upon the applied boundary conditions. The last strain in (5) deems all strains generated due to the chemical reactions and other effects.

$\epsilon:=\epsilon^{\mathcal{M}_{e}}+\epsilon^{\mathcal{M}_{p}}+\epsilon^{\mathcal{T}}+\epsilon^{\mathcal{H}}+\epsilon^{\mathcal{C}}$

where $\quad \epsilon \in \operatorname{Sym}(3) \subset \mathbb{R}^{3} \times \mathbb{R}^{3}, \epsilon^{\mathcal{M}_{e}} \in \operatorname{Sym}(3) \subset \mathbb{R}^{3} \times \mathbb{R}^{3}, \epsilon^{\mathcal{M}_{p}} \in \operatorname{Sym}(3) \subset \mathbb{R}^{3} \times \mathbb{R}^{3}$, $\epsilon^{\mathcal{T}} \in \operatorname{ISO}(3) \subset \mathbb{R}^{3} \times \mathbb{R}^{3}, \epsilon^{\mathcal{H}} \in \operatorname{ISO}(3) \subset \mathbb{R}^{3} \times \mathbb{R}^{3}$ and $\epsilon^{\mathcal{C}} \in \mathbb{R}^{3} \times \mathbb{R}^{3}$ are the total strain tensor, elastic strain, plastic strain, thermal strain tensor, moisture-induced strain tensor and chemical-based strain tensor, respectively. The above-mentioned strains are symmetric second-rank tensors in accordance with the Cauchy-Boltzmann continuum media assumptions. The thermal stress tensor $\left(\epsilon^{\mathcal{T}}\right)$ could be well approximated in terms of temperature variation $(\Delta T)$.
} 
$\bar{\epsilon}:=\bar{\epsilon}^{\mathcal{M}}+\bar{\epsilon}^{\mathcal{C}-\mathcal{H}}$

where

$\bar{\epsilon}^{T}=\nabla u-\bar{A} \quad$ and $\quad \bar{\epsilon}^{\mathcal{C}-\mathcal{H}}=\alpha^{\mathcal{C}-\mathcal{H}} \cdot \Delta \Pi \cdot \mathbf{1}$

where $\quad \bar{\epsilon}^{\mathcal{M}} \in \operatorname{Sym}(3) \subset \mathbb{R}^{3} \times \mathbb{R}^{3}, \quad \bar{\epsilon}^{\mathcal{C}-\mathcal{H}} \in \operatorname{ISO}(3) \subset \mathbb{R}^{3} \times \mathbb{R}^{3}$, $\nabla u:=(\nabla \otimes u)^{T}=\in \mathbb{R}^{3} \times \mathbb{R}^{3}, \quad \bar{A} \in \mathfrak{s} 0(3) \subset \mathbb{R}^{3} \times \mathbb{R}^{3}, \quad \mathbf{1}:=\delta_{i j} \hat{e}_{i} \otimes \hat{e}_{j}$ $\in \operatorname{ISO}(3) \subset \mathbb{R}^{3} \times \mathbb{R}^{3}, \Delta \Pi \in \mathbb{R}$ and $\alpha^{\mathcal{C}-\mathcal{H}}$ are the elastic mechanical strain tensor, infinitesimal chemo-hygric strain tensor, gradient of displacement vector, dual vector of the micro-rotation vector, second-rank identity tensor, relative humidity variation and chemohygric expansion coefficient, respectively. By substituting the mechanical strains obtained from (7) into (3c), new constitutive laws can be inferred as following (see Appendix B):

$\sigma=\lambda \operatorname{tr}[\bar{\epsilon}] \mathbf{1}+2 \mu \operatorname{sym} \bar{\epsilon}+2 \mu_{c}$ skew $\bar{\epsilon}-\overbrace{\alpha^{\mathcal{C}-\mathcal{H}}(3 \lambda+2 \mu) \Delta \Pi \cdot \mathbf{1}}^{\chi:=\alpha^{\mathcal{C}-\mathcal{H}}(3 \lambda+2 \mu) \Delta \Pi \cdot \mathbf{1}}$

and

$m=\gamma \nabla \phi+\beta(\nabla \phi)^{T}+\alpha \operatorname{tr}[\nabla \phi] \cdot \mathbf{1}$

where $\chi \in \operatorname{ISO}(3) \subset \mathbb{R}^{3} \times \mathbb{R}^{3}$ is a pseudo Duhamel-Neumann's second-rank tensor or called hygro-Cosserat Duhamel-Neumann's tensor (see [39] for more detail).

\section{Random aggregate distribution through cement paste matrix}

\subsection{General motivation}

The definition of a realistic geometry suitable for the description of the meso-structure of cement-based materials includes a bunch of studies in the literature. One way to use more realistic geometry is to take advantage of the spherical packing methods including the homogenization technique and/or damage analysis $[62,63]$. Basically, the spherical packing issue has been treated by means of the following approaches (see [64] for more details):

\section{Dynamic simulation approach using iterative growth algo- rithm $[65,66]$. \\ 2. Geometric approach ([67-69] and lately [64,70]).}

The dynamic simulation approach is used to prepare the sample geometries for soil $[71,72]$, concrete [73,74], powders [75], Van der Waals forces [76] and cohesion problems [77]. Alternatively, the geometric methods have been proposed and taken into account for the random spherical packing issue. ${ }^{7}$

Remark 1. The geometric approach is not only more stable (mechanical aspects) but also it is much faster than the dynamic simulation approach. Nevertheless, the geometric approach is less stochastic than the other approach. That is why we call it as pseudo-random spherical packing herein.

The main goal is to mimic and create the geometry as close as possible to the real mortar meso-structure. This geometry can be used to go the further stages, i.e. numerical modeling.

\subsection{Pseudo-randomly motivated $3 D$ spherical packing: brief review of the very early algorithm}

In the current contribution, we deem a simplified geometry in which one can readily distinguish the inclusions and cement paste

\footnotetext{
7 The geometric approach can be readily applied to the large scale spherical issue as a suitable approach. These spherical packings are widely used to build the Discrete Element Method (DEM) modeling of the complex geometrical configurations [64,70]. Based upon the above-mentioned concept, YADE code was developed (see https:// yade-dem.org/wiki/Yade for more detail).
}

altogether. By taking advantage of the geometric spherical packing algorithm involving FEM free tetrahedral mesh generator algorithm, we can create a pseudo-random spherical packing with random radii including the sphere overlapping restrictions. It is also possible to reduce the FEM mesh density to reach the target aggregate-to-cement ratio $\left(\frac{A}{C}\right)$. The latter tune-up during the spherical packing generation sustains both main objectives, i.e. the morphological and topological issues. The main steps of the spherical grains generation could be summarized as follows:

1. The cement paste cell generation, e.g. cubic cells.

2. The free tetrahedral meshing via the usual built-in mesher algorithms.

3. The determination of center and radius of the spherical grains using the available mesh nodes and tetrahedral side lengths.

4. The verification of the overlapping zones and some additional boolean operations.

5. The evaluation of the extracted target aggregate-to-cement ratio $\left(\frac{A}{C}\right)$.

6. The previous meshes and nodes removal and mesh generation for the newly obtained geometry.

In Fig. 4, some steps are illustrated. In the current study, we use an easy-to-use and fairly simple steps in extracting the final geometry. More importantly, the DEM (grains inclusions) and FEM (cement paste matrix) are taken into account altogether. One of the most outstanding feature of the aforementioned mixture of these methods is that one can get more realistic outcomes in the sense that both cement paste matrix and grains are elastic solids and the interfacial zone (ITZ) stress assessment would be better than the other assumptions, e.g. rigid-solid interaction in the cement paste mixture. ${ }^{8}$

\section{Experimental study}

\subsection{Materials and test methods}

To investigate the impact of the chemical composition and physico-chemical properties of cement on the autogenous deformations via the numerical modeling, the early-age behavior of three cementitious matrices has been taken into account. The volumetric autogenous shrinkage and Young's modulus measurement are performed on the cement paste samples at very early-age, during the first $72 \mathrm{~h}$ after the mixture preparation. The mortars are also prepared with the same cement pastes in order to observe the micro-structure of the early-age cementitious matrices in the vicinity of aggregates, using Scanning Electron Microscopy (SEM).

The applied cements are a CEMI $52.5 \mathrm{~N}$ Portland cement (named as CEMI) and two blended cements, one with $24 \%$ of limestone filler (CEMII $32.5 \mathrm{R}$, named as CEMII), and the other containing $62 \%$ of blast furnace slag (CEMIII/A $42.5 \mathrm{~N}$, named as CEMIII). Their composition and physico-chemical properties are given in Table 2 . The sand used for the mortar preparation was a 0/2-mm standardized siliceous sand from Leucate, France (EN 196-1). It was composed of $97 \%$ silica and 3\% quartz-schist and its absolute density is equal to $2650\left[\frac{\mathrm{kg}}{\mathrm{m}^{3}}\right]$.

The cement pastes and mortars are prepared with the same $\frac{W}{C}$ mass ratio, $\left(\frac{W}{C}=0.30\right)$, and the aggregate-to-cement $\left(\frac{A}{C}\right)$ mass ratio in mortars $\left(\frac{A}{C}=1\right)$. The preparation procedure is similar for all cement pastes and mortars: the mixtures are obtained by mixing the

${ }^{8}$ The grains generator algorithm and aggregate-to-cement ratio tune-up matter are still at the early stages and some further enhancements are required to mimic the reality as far as possible [78]. Anyway, the described methodology is good enough to capture the reality of the early shrinkage of the cement pastes very often. 


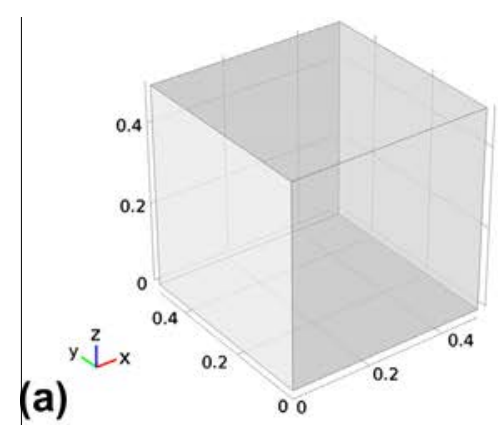

(b)
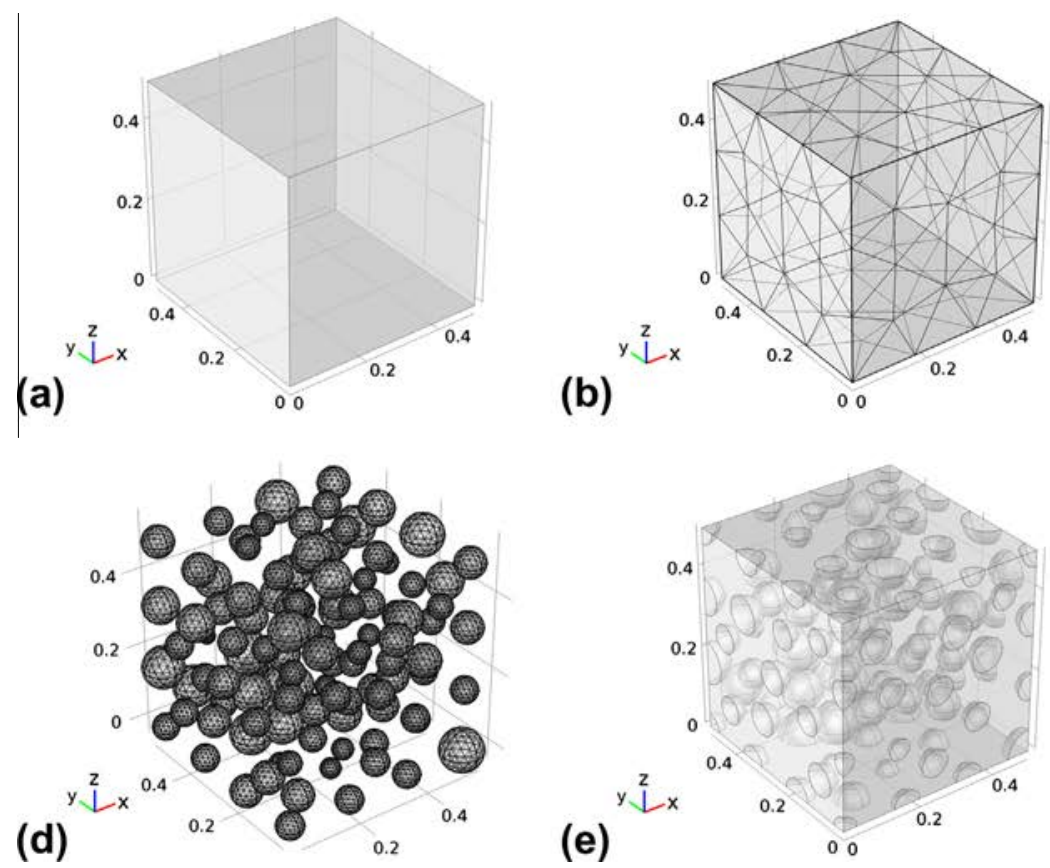

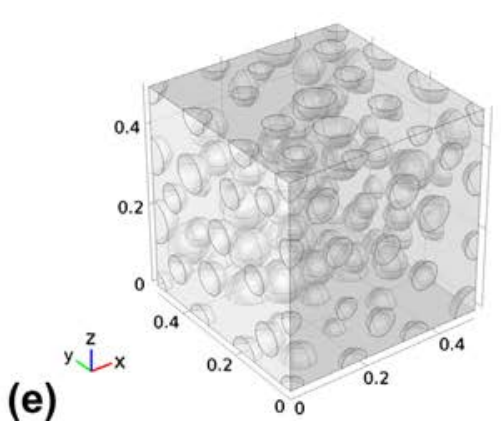

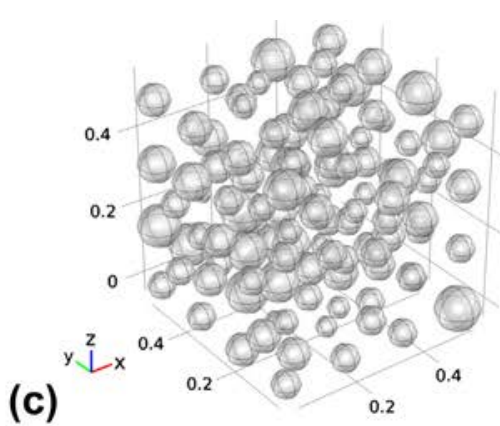

(f)

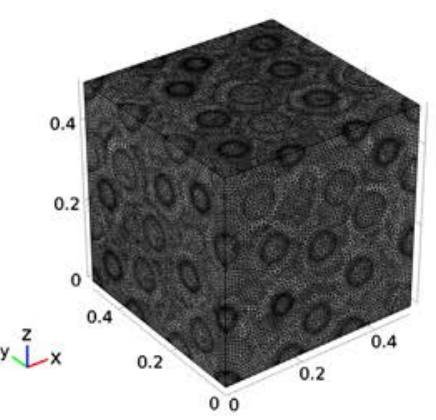

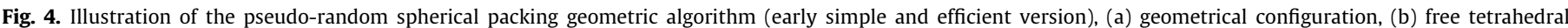

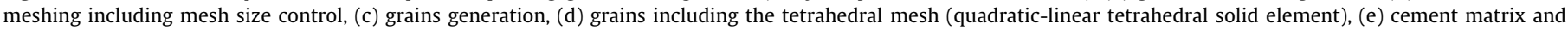
grains and (f) cement matrix and grains including the tetrahedral mesh (quadratic-linear tetrahedral solid element).

solid constituents with tap water at $20 \pm 2{ }^{\circ} \mathrm{C}$ in a 5 - $\mathrm{L}$ mixer during $3 \mathrm{~min}$. The autogenous shrinkage is measured upon the hydrostatic weighing tests on cement paste samples cast in latex membranes and immersed in a $20^{\circ} \mathrm{C}$-thermostated water bath. The samples were rotated during the whole test period using a rotational waterproof device in order to avoid bleeding of the cement pastes $[11,79]$.

The dynamic Young's modulus has been extracted via the impulse excitation tests achieved by means of the Grindosonic device on cement paste prismatic specimens $(160 \times 40 \times 40[\mathrm{~mm}])$ at $20 \pm 2{ }^{\circ} \mathrm{C}$. The specimens were wrapped with several self-adhesive aluminum layers to avoid drying and ensure sealed curing conditions. Before each test, two small zones of the specimens are uncovered to apply a light and elastic impact and the flexural resonant frequency of the signal is monitored either. The mean value of three readings of the flexural resonant frequencies is utilized to determine the dynamic Young's modulus [80].

The micro-structure of the cement paste surrounding aggregates is investigated on the mortar samples using a Scanning Electronic Microscope (SEM). The observations are performed on 48 h-aged specimens, which are wrapped in a polyethylene film to avoid drying, and kept at $20 \pm 2{ }^{\circ} \mathrm{C}$, until the moment of testing. The precise description of the testing procedures can be found out in the previous studies [15,39].

\subsection{Experimental results analysis}

Fig. 5a and b represent the experimental curves of autogenous shrinkage and dynamic Young's modulus for our cement pastes, respectively. The early-age autogenous shrinkage (or external shrinkage [81]) curves generally show two main phases: a first phase with a high shrinkage rate that develops from the mixing to the setting period, followed by a second phase characterized by a lower strain rate. These two phases can be clearly identified in Fig. 5a for the studied cement pastes. During the first phase, the material is nearly saturated with water and the volume variations are mainly due to the chemical shrinkage. The progressive consumption of water, which initially fills the pores, and the formation of the solid mineral skeleton cause the development of internal cavities (see [33] for more details). These self-desiccation phenomena and cavitations give rise to capillary pressure or socalled matric pressure during and after the setting period. This matter induces a global contraction of the solid skeleton, called as the self-desiccation deformations.

Fig. 5a shows that, at $60 \mathrm{~h}$, the autogenous deformation of CEMIII cement paste is about 2.7 times greater than the CEMII paste and 1.7 times greater than the CEMI paste. This gap is partly due to the first phase of the autogenous shrinkage curve ("chemical" phase) of our cement pastes. The chemical part of deformations is much higher for CEMIII cement and extends over a longer period. Several authors also found out that the use of ground granulated blast furnace slag in the cement usually causes a significant increase in the early-age autogenous shrinkage [2-4,82]. This phenomenon is explained very often by a higher chemical shrinkage [15], a finer pore distribution [5], and a slower evolution of stiffness of cementitious matrices containing slag, as shown in Fig. 5b. Among the aforementioned cements, the CEMII cement exhibits lower autogenous shrinkage than the others: this may arise from a dilution effect of limestone filler on chemical shrinkage [15] and self-desiccation, leading to a decrease of autogenous deformations, in comparison with the CEMI cement.

Concerning the dynamic Young's modulus outcomes (Fig. 5b), the evolution of the curves of our chosen cement pastes can be divided into three main phases: a first phase of "zero" stiffness (before the setting of the material), followed by a second phase of rapid change in the stiffness (from setting to $48 \mathrm{~h}$ ), and, beyond $48 \mathrm{~h}$, a third phase of slower evolution. This third phase mainly appears due to a change in the cement hydration process, which passes from a relatively rapid nucleation-growth process of hydrates to a slower process of controlled diffusion when the thickness of the layers of CSH reduces the water accessibility to the unhydrated cement particles. The CEMI cement, richer in clinker than the CEMII and CEMIII ones, shows higher stiffness (Fig. 5b). At $72 \mathrm{~h}$ of hydration, the magnitude of stiffness of the 
Table 2

Chemical and general properties of chosen cements.

\begin{tabular}{|c|c|c|c|}
\hline $\begin{array}{l}\text { Mineralogical } \\
\text { composition (weight\%) }\end{array}$ & $\begin{array}{l}\text { CEMI } \\
52.5(-)\end{array}$ & $\begin{array}{l}\text { CEMII/B-LL } \\
32.5(-)\end{array}$ & $\begin{array}{l}\text { CEMIII/A } 42.5 \\
\text { (clinker, slag) }\end{array}$ \\
\hline $\mathrm{CaO}$ & 64.35 & 62.00 & $50.40,43.37$ \\
\hline $\mathrm{SiO}_{2}$ & 20.20 & 15.90 & $29.12,36.96$ \\
\hline $\mathrm{Al}_{2} \mathrm{O}_{3}$ & 4.85 & 3.90 & $8.85,11.33$ \\
\hline $\mathrm{Fe}_{2} \mathrm{O}_{3}$ & 2.80 & 2.15 & $1.02,0.4$ \\
\hline $\mathrm{MgO}$ & 0.90 & 0.80 & $5.35,7.33$ \\
\hline $\mathrm{SO}_{3}$ & 3.05 & 2.85 & $2.49,1.53$ \\
\hline $\mathrm{Na}_{2} \mathrm{O}$ & 0.16 & 0.14 & $0.19,0.27$ \\
\hline $\mathrm{K}_{2} \mathrm{O}$ & 0.98 & 0.80 & $0.70,0.42$ \\
\hline Ignition loss & 1.65 & 11.05 & $1.5,-$ \\
\hline Insoluble residue & 0.22 & 0.45 & $0.19,-$ \\
\hline Active alkalis & 0.80 & 0.70 & $0.65,-$ \\
\hline Free $\mathrm{CaO}$ & 1.30 & 0.84 & $0.52,-$ \\
\hline Blaine surface area $\left(\mathrm{cm}^{2} / \mathrm{g}\right)$ & 3390 & 3950 & $4300,-$ \\
\hline Bogue composition (weight) & - & - & - \\
\hline $\mathrm{C}_{3} \mathrm{~S}$ & 62.01 & 45.22 & 67.5 \\
\hline $\mathrm{C}_{2} \mathrm{~S}$ & 11.13 & 11.47 & 10.7 \\
\hline $\mathrm{C}_{3} \mathrm{~A}$ & 8.11 & 6.70 & 2.64 \\
\hline $\mathrm{C}_{4} \mathrm{AF}$ & 8.45 & 6.49 & 12.8 \\
\hline Gypsum & 6.56 & 5.70 & - \\
\hline
\end{tabular}

CEMI paste is about 1.3 and 1.4 times larger than those of CEMII and CEMIII pastes, respectively.

\subsection{Time-zero of self-desiccation shrinkage}

The previous sub-section highlighted the existence of two phases in the evolution of autogenous shrinkage. The second phase, corresponding to self-desiccation shrinkage, is of interest in investigating the development of early-age self-induced stress. As a matter of fact, the first phase mainly deals with the chemical shrinkage and develops before the setting while the material is still plastic. During this period, the material behaves as a concentrated mineral suspension, whose free deformations do not sustain the stress development through the cement matrix. Therefore, it is necessary to define a "time zero" to separate the chemical part from the "self-desiccation" part of autogenous shrinkage. The determination of time-zero is fundamental for the computation of self-induced stresses and several studies have been dedicated to this issue $[33,83-86]$.

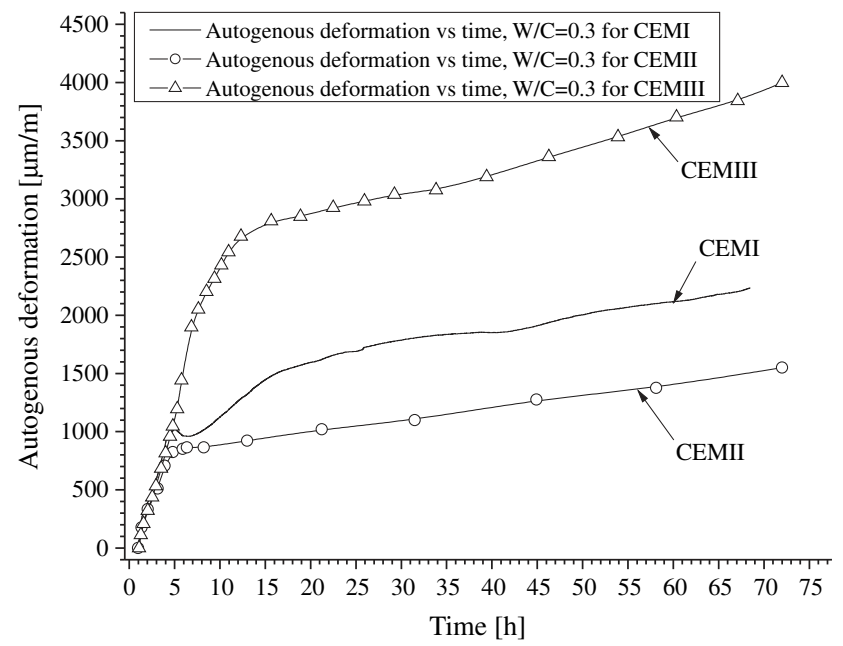

(a)
Sant et al. [84] proposed to use various analysis procedures of chemical shrinkage and autogenous strain data to identify the "time zero". They found a reasonable correlation between timezero obtained from these procedures and the values determined by the electrical conductivity and acoustic emission tests. Lately, Sant et al. [86] compared the performances of various techniques (chemical and autogenous shrinkage, calorimetry, rheology, electrical conductivity and ultrasonic pulse conduction) in identifying the fluid-solid transition in cementitious systems and observed that the solidification is detected within a similar time interval. However, these studies solely focused on CEMI.

In the present study, time zero is determined from the measurement of the stiffness evolution using impulse excitation tests performed with the Grindosonic device. During the first hours of hydration, the stiffness of the cement pastes remained close to zero. It is assumed that the fluid-to-solid transition corresponded to the moment when the stiffness begins to grow drastically. For each cement, this moment is determined as the intersection point between the linear extrapolated experimental curve and time axis. This gives rise to $3.4 \mathrm{~h}, 5.1 \mathrm{~h}$ and $6.5 \mathrm{~h}$ for CEMI, CEMII and CEMIII cements, respectively. It is worth noting that this time-zero takes place during the Vicat setting time period of the cements, except for CEMIII cement. For this cement, it was observed that the time-zero corresponds approximately to the knee-point marking the transition between chemical shrinkage and self-desiccation shrinkage (see [15] for more details).

The time-zeroed curves are plotted in Fig. 6: the initial order of the curves (CEMII < CEMI < CEMIII, see Fig. 5a) can be clearly distinguished. Fig. 6 shows that, at $60 \mathrm{~h}$, the initialized self-desiccation strain of CEMIII cement paste is about 3.4 times greater than the CEMII paste and 1.3 times greater than the CEMI paste. Finally, these curves are used as the input data for the numerical computations of self-induced stresses through the considered cement pastes.

\subsection{Micro-structure of the interfacial zone between cement paste and aggregates}

Fig. 7 provides the SEM micrographs made on the interfacial transition zone between the matrix and the aggregates for our three different cement pastes at $48 \mathrm{~h}$ of hydration. It is important to note that the samples were kept in the autogenous conditions and at constant temperature until the time of testing. However, the preparation protocol of the samples included a 4-h drying sequence at $40{ }^{\circ} \mathrm{C}$ and a polishing sequence of the surfaces observed,

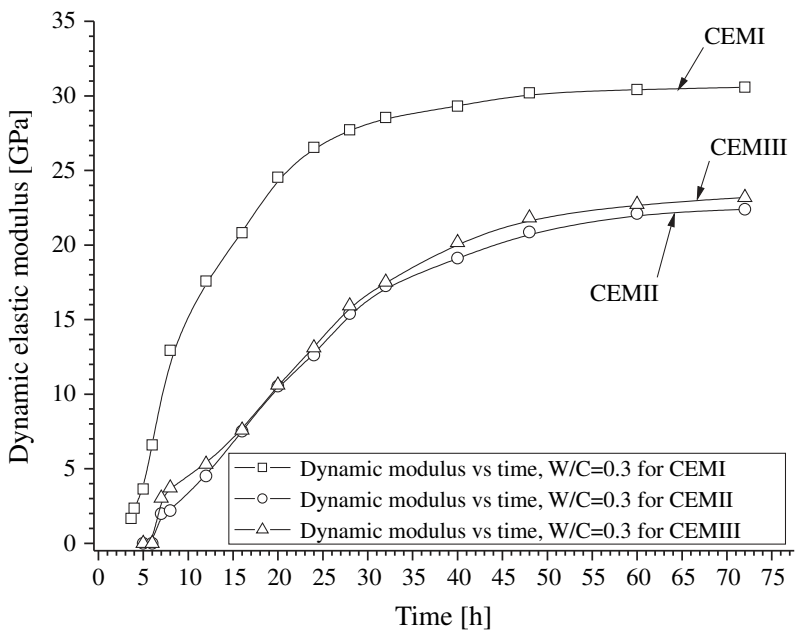

(b)

Fig. 5. Experimental results for CEMI, CEMII and CEMIII cement pastes $\left(\frac{W}{C}=0.3\right)$, (a) autogenous shrinkage and (b) dynamic Young's modulus. 


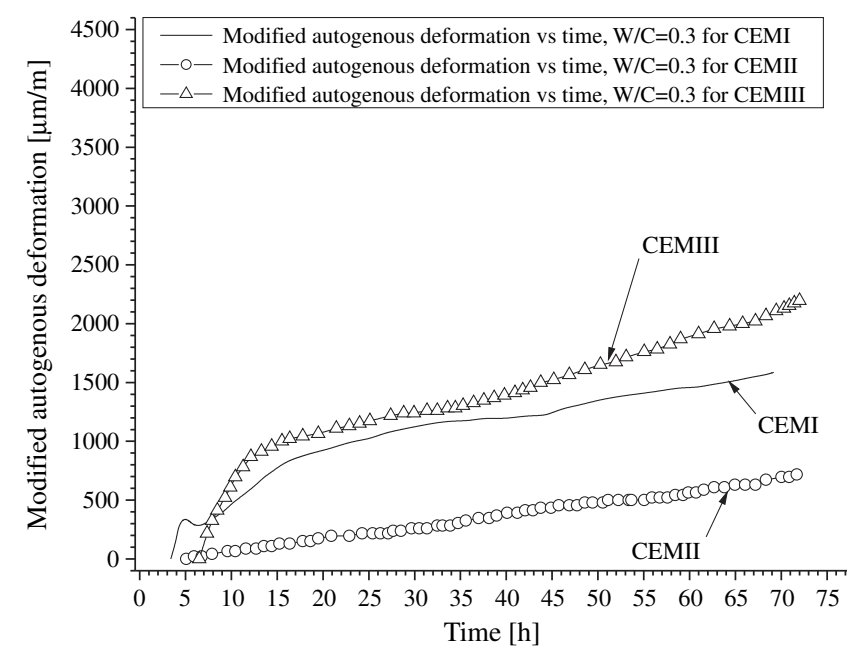

Fig. 6. Initialized volumetric autogenous shrinkage or so-called modified autogenous deformation versus age of cement pastes in hours $\left(\frac{W}{C}=0.30\right)$.

before the introduction in the SEM chamber. In spite of all painstaking efforts during the experiments, such operations could induce micro-cracks in the matrix. To evaluate these potential artifacts, the SEM observations are achieved on a CEMI cement paste sample, with no aggregates, using the same protocol. On this cement paste sample, no microscopic cracks are detected [15]. Hence, it is assumed that the development of micro-cracks observed in mortars (Fig. 7) is mainly related to the restraining effect of aggregates on the cement paste autogenous shrinkage. The autogenous micro-cracking results from the partial restraint of cement paste strain due to the presence of aggregates: it depends on the simultaneous evolution of autogenous deformation and gain of stiffness of the cement paste, leading to the development of selfinduced stresses. When these stresses exceed the tensile strength of the matrix, micro-cracking appears. From this point of view, Fig. 8 shows a clear influence of the cement type on the microstructure of the cement paste surrounding the aggregates. The CEMI cement paste, which exhibits the higher stiffness at earlyage (Fig. 5b) but not the higher autogenous strains (Fig. 5b), is characterized by a very pronounced network of interconnected radial and tangential micro-cracks (Fig. 7a). The opening width of these micro-cracks is between 0.3 and $2 \mu \mathrm{m}$. The CEMIII cement paste shows the higher shrinkage rate but a lower stiffness comparing to the CEMI cement paste. This also presents some microcracks but with both lower density and lower average opening width $(0.2-1.5 \mu \mathrm{m})$. Among the investigated cements, CEMII seems to be less sensible to the early-age micro-cracking. These observations demonstrate that the measurement of free shrinkage is not sufficient to assess the risk of early-age micro-cracking of cement paste. Therefore, a numerical approach is necessary to handle the complexity of mechanisms involved and improve the understanding of early-age behavior of cement pastes. The next section deals with the analysis of the results obtained from the modeling described herein.

\section{Numerical experiments}

\subsection{D-FEM hygro-Cosserat modeling of CEMI, CEMII and CEMIII}

To pursue the hygro-Cosserat modeling of our chosen mortars, i.e. CEMI, CEMII and CEMIII, one-eight symmetry assumption has been used throughout the computations herein (Fig. 8). The pseudo-random spherical packing considering the appropriate aggregate-to-cement ratio $\frac{A}{C}$ is taken into account (Fig. 9). The autogenous deformation measurements during the very early-age as well as the size-independent mechanical properties variations are deployed in the forthcoming computations. As pointed out earlier, the autogenous deformations are considered as a bulk strain tensor by neglecting the shear strains, i.e. the autogenous shear strain components are considered to be very small. It is well worth noting that the pseudo-randomly generated geometry is utilized for our selected mortars, i.e. the mortars using CEMI, CEMII and CEMIII. Therefore, the pseudo randomly-motivated geometry including the matrix and grains remains the same throughout the current mesoscopic numerical modeling and only the material properties are different. This approach helps us to wipe out the geometrical issues from the material-based effects. Based upon our numerical experiments for the cement mortars, it seems that the extreme values (minimum and maximum internal stresses) are not substantially affected via the grain shapes. ${ }^{9}$ It is of great importance to remark that the discretization issue has been carried out by means of the isoparametric quadratic-linear Lagrange shape functions, i.e. quadratic shape function for displacement vector $u \in \mathbb{R}^{3}$ and linear shape function for micro-rotation vector $\phi \in \mathbb{R}^{3}$ (Fig. 10).

Remark 2. In the generalized continuum mechanics, we must verify the mesh-independency issue, i.e. the number of elements should not manipulate the results. This issue and convergence of the problems have been evaluated in the current study. However, we abstain to present more detail herein (see $[45,56]$ for more details pertaining to the non-linear and linear Cosserat theory convergence and mesh-independency).

\subsection{D-FEM results for CEMI, CEMII and CEMIII}

The SEM observations at $48 \mathrm{~h}$ after mixing action for different cement types in Fig. 7 emphasizes the role of chemical composition and its impact on the stress development and consequently the micro-cracking phenomenon. This matter can be investigated using the numerical modeling of a pseudo-stochastic mixture of cement paste and sand grains at meso-scale. Furthermore, the use of experimental techniques does not always undertake these observations in a continuous manner or it would take too much efforts. That is why the numerical experiments are relevant way to cover these issues.

In Fig. 11, CEMI, CEMII and CEMIII are illustrated at $48 \mathrm{~h}$ after the hydration. As shown in Fig. 11, the internal stress development through the CEMII matrix is less than CEMI and CEMIII. Therefore, one can expect less micro-cracking for CEMII matrix comparing to the others. The SEM observation at $48 \mathrm{~h}$ after hydration is fairly agreed with the 3D-FEM outcomes (Fig. 7).

Considering the same pseudo-random geometry, the mesh density and boundary conditions for CEMI, CEMII and CEMIII, the stress development across the cement paste in CEMI is slightly greater than CEMIII. The high stress development zones are positioned around the sand grains very often. Evidently, this comes up from the hindering effects of sand gains against the cement matrix bulk deformation.

In Fig. 12, once again, the internal stress distributions of the CEMI, CEMII and CEMIII specimens are highlighted. The internal stress distributions are displayed as median slices ( $x y$-slice at

\footnotetext{
${ }^{9}$ Evidently, very smooth spherical grains are taken into account herein. The smooth ellipsoidal aggregates with random orientations could be considered as well. The use of irregular and stochastic shapes for the grains would be the most realistic case. However, this drastically increases the size of problem and a huge amount of DOFs must be solved via our parallel implementations. The problem gets worse when we deal with the Cosserat theory whose application implies more DOFs comparing to the classical theory or Cauchy-Boltzmann's theory. Furthermore, this entails some further discrepancies in conjunction with the analytical geometry creation.
} 


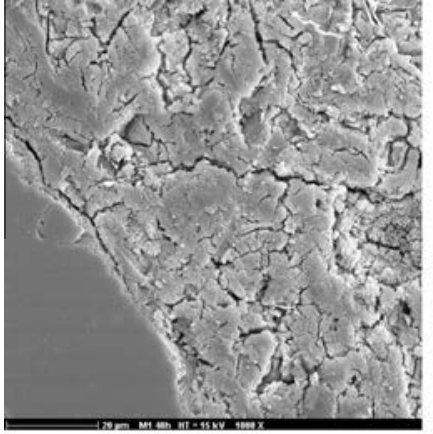

(a)

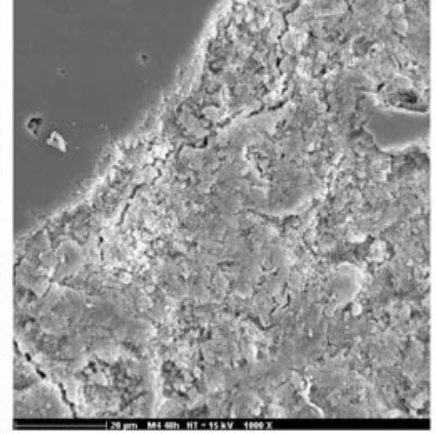

(b)

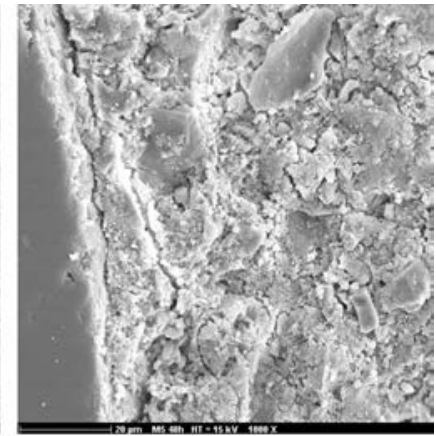

(c)

Fig. 7. SEM images of our mortar and micro-cracking observations $\left(\frac{W}{C}=0.30 ; \frac{A}{C}=1 ; 48 \mathrm{~h}\right.$ after mixing) (a) CEMI, (b) CEMII and (c) CEMIII.

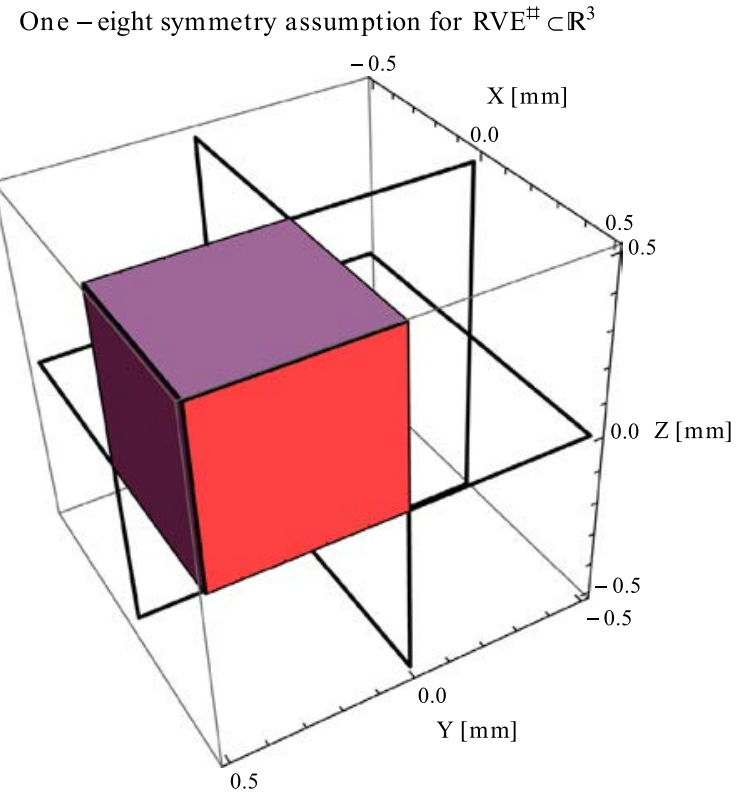

Fig. 8. One-eight symmetry assumption for the 3D-FEM hygro-Cosserat elasticity modeling using three planes of symmetry.

$z=0.25[\mathrm{~mm}])$. The internal stress curves are plotted for the same positions including the same mesh density. These curves substantiate that the stress development in CEMI is a little greater than CEMIII. Some numerical oscillations can be also seen in Fig. 12. This is due to the discretization issue. These numerical noises could be neatly wiped out while more mesh density was applied for the computations. This matter leads to very huge computations, which are out of scope of the current paper.

The use of fairly dense mesh densities usually fulfill the above-mentioned requirement. That is why the mesh density for all computations are restricted to only $2.5 \mathrm{Mi}$ DOFs in which the computations are fairly affordable and less numerical noises can be expected. The 18-node solid elements (Fig. 10b) are utilized for CEMI, CEMII and CEMIII in the present study.

It is well worth mentioning that the mesh density has been gradually increased from $0.3 \mathrm{Mi}$ to $2.5 \mathrm{Mi}$ for CEMI, CEMII and CEMII. As indicated before, the use of an appropriate mesh density can perfectly provide the smoother stress development graphs.

As illustrated in Fig. 12b, d and f, the stress distribution through the cement matrix steadily grows and it exceeds the tensile strength of cement pastes except CEMII. As a matter of fact, CEMII does not provide the micro-cracking network at $48 \mathrm{~h}$ and one can expect the same trend beyond $48 \mathrm{~h}$ until $96 \mathrm{~h}$ after hydration.

\section{Results synthesis}

In Fig. 12, the higher stress development zones are generally positioned around the sand grains, and these self-induced stresses sharply decrease when moving away from the aggregates. Evidently, this comes up from the hindering effects of sand grains against the cement matrix bulk deformation. This stress-distribution is in agreement with the conclusions of Goltermann [34], who demonstrated that the stresses in cement paste take the largest values next to the aggregates margin. As displayed in Fig. 12, the rapid increase of self-generated stresses at early-age (between 12 and $48 \mathrm{~h}$ of hydration) can be seen due to the simultaneous increase of autogenous deformation and stiffness of cement pastes during the first days of hydration.

The computed stress values obtained after $48 \mathrm{~h}$ of simulated hydration are high: between $-46[\mathrm{MPa}]$ (compression) and 39 [MPa] (tension) for the CEMI cement paste, between -11 and 8 [MPa] for CEMII and between -49 and 36 [MPa] for CEMIII (Fig. 11). These high values could be due to the fact that the computations did not take into account the stress relaxation related to the viscoelastic behavior of cement-based materials. Indeed, several researchers showed that the stress relaxation due to creep phenomena could significantly reduce self-induced stress in early-age cementitious systems (see Lura et al. [88] and Darquennes et al. [7]). However, the accurate modeling of cement paste creep at early-age remains a complex task and out of the scope of the present study. Further works are currently in progress to develop this aspect in our modeling approach. We emphasize these aspects in the next section.

Considering the same pseudo-random geometry, the mesh density and boundary conditions for CEMI, CEMII and CEMIII, numerical results show that the stress development through the CEMII matrix is far lower than for the CEMI and CEMIII ones. Therefore, one can expect less micro-cracking for CEMII matrix, comparing to the others. The SEM observation at $48 \mathrm{~h}$ after hydration is fairly agreed with the 3D-FEM outcomes (Fig. 7): as a matter of fact, CEMII cement does not exhibit visible micro-cracking network. As pointed out earlier, the numerical results also reveal relatively close self-induced stress values for CEMI and CEMIII cements, even if the stress development across the CEMI cement paste is slightly greater than for the CEMIII one. Consequently, a similar risk of early-age cracking for these two cements would be expected. However, two important parameters ought to be taken into account when considering the risk of autogenous micro-cracking of cement-based materials, i.e. the tensile strength and the stress relaxation capacity. The previous 

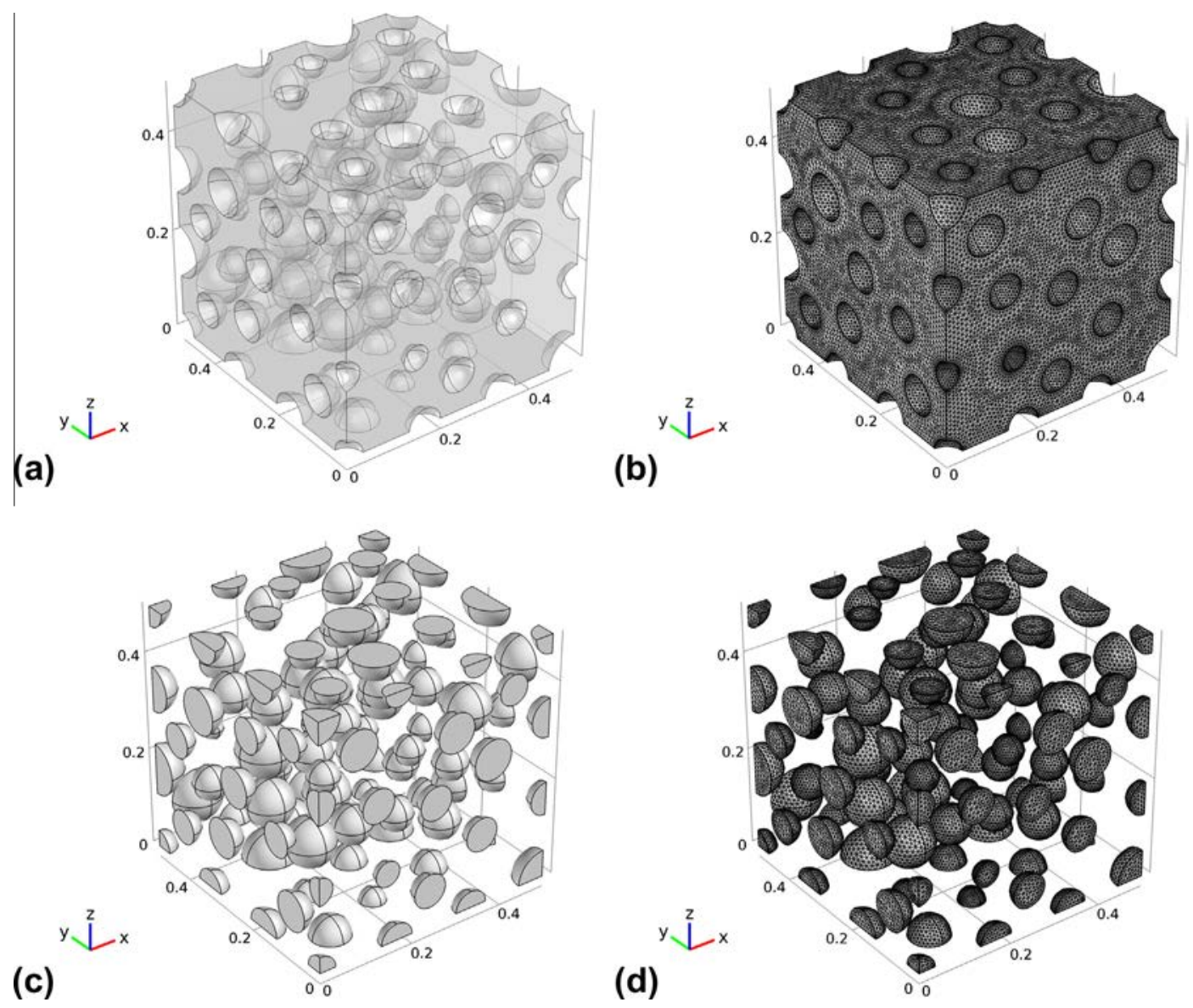

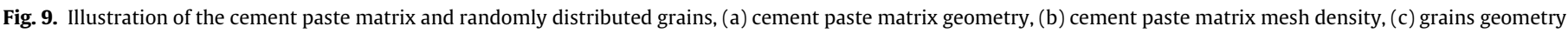
and positions across the cube cell and (d) grains mesh density.

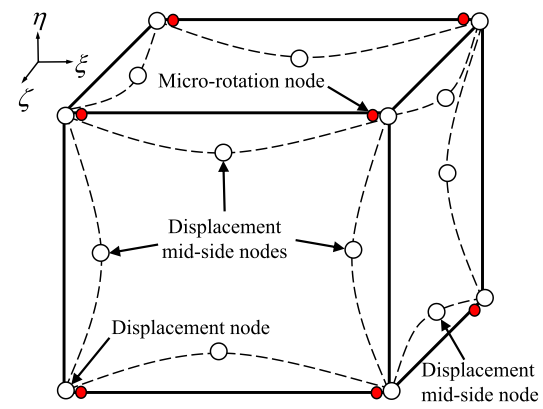

(a)

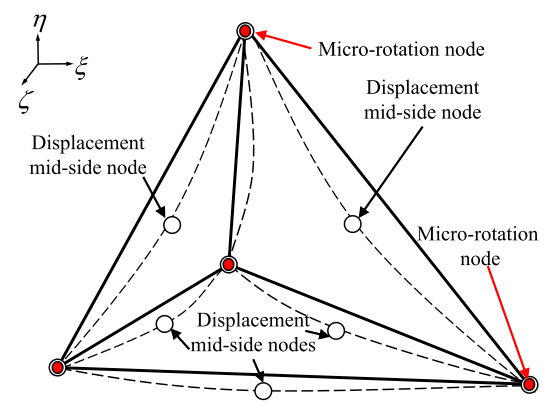

(b)

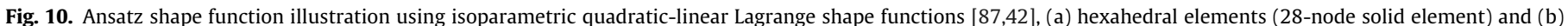
tetrahedral elements (18-node solid element) [56].

results have shown that the CEMIII cement paste considered in this study has slightly lower tensile strength values than the CEMI cement paste [15]. Concerning the stress relaxation, the effect of slag strongly depends on its content in cement: according to Lura [6] and Darquennes et al. [7], blended cement with slag content from $42 \%$ to $76 \%$ slag seems to present larger capacity for relaxing tensile stresses at early-age, whereas Pane and Hansen [89] observed that the relaxation of concrete containing cement with only $25 \%$ of slag did not significantly differ from OPC concrete. For the composition of blended cement considered here ( $62 \%$ of slag), it may be supposed that the stress relaxation properties of CEMIII cement paste were greater than CEMI. This is confirmed by the SEM observations in Fig. 7, showing that the CEMI cement paste surrounding the aggregates seems much more sensitive to cracking than the CEMIII cement paste.

Concerning the magnitude of computed stress values, the comparison with the experimental data available in the literature is not evident, because of the stress relaxation phenomenon mentioned earlier and which is not considered in the model, but also because self-induced stresses are usually measured on concrete specimens 


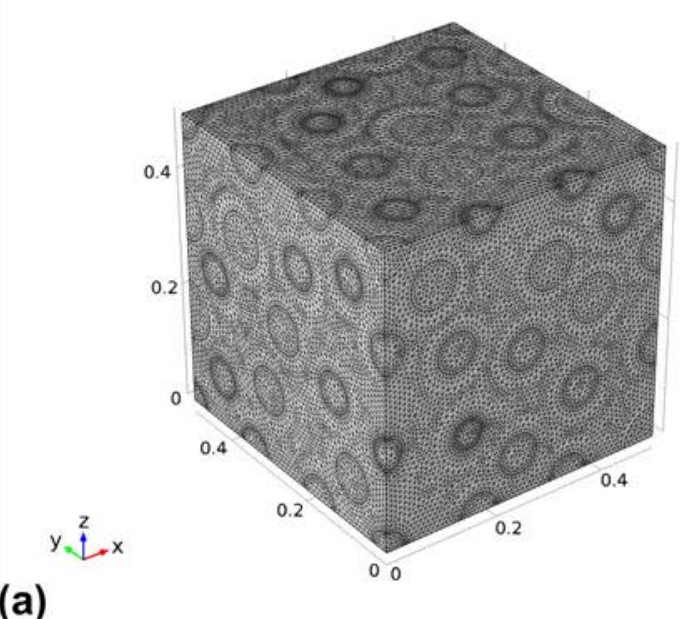

(a)

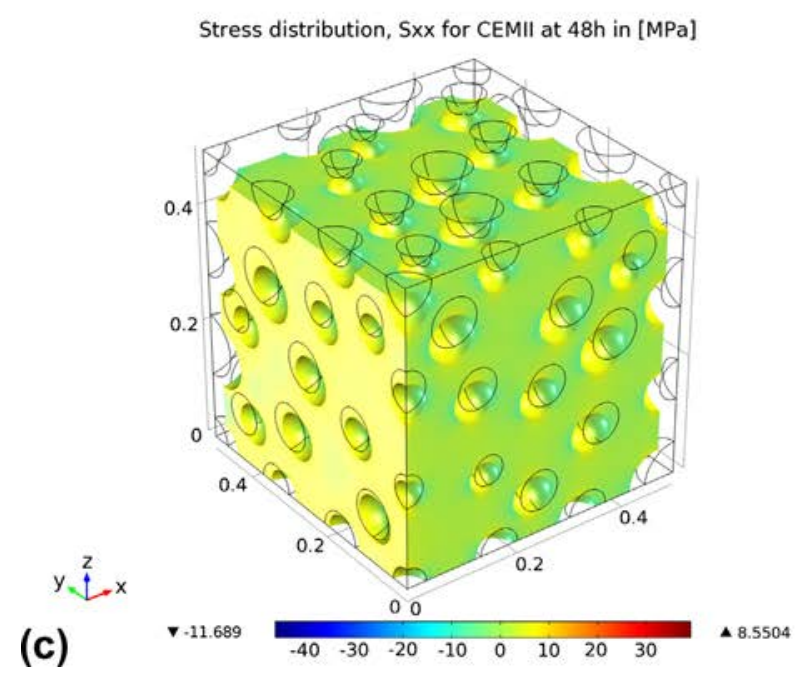

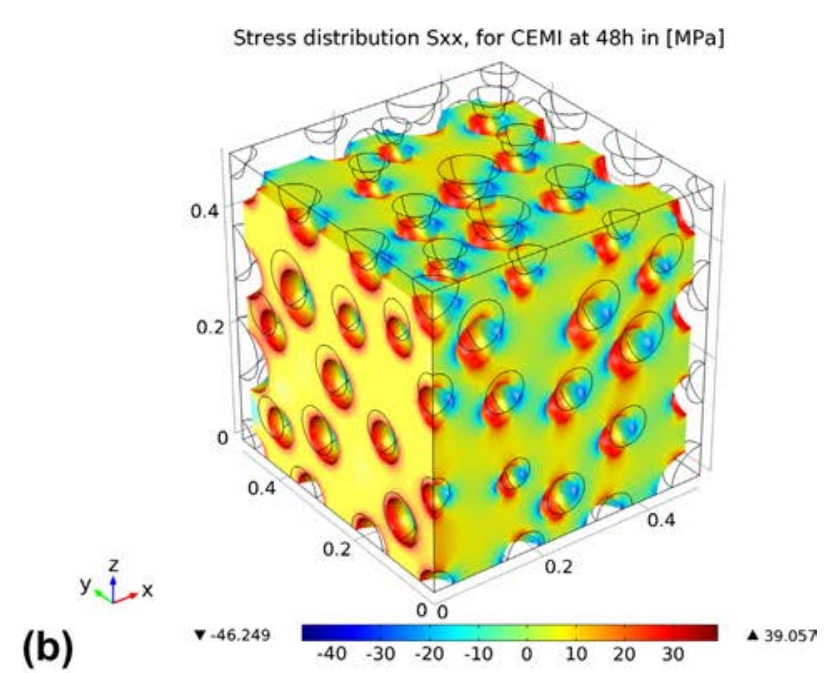

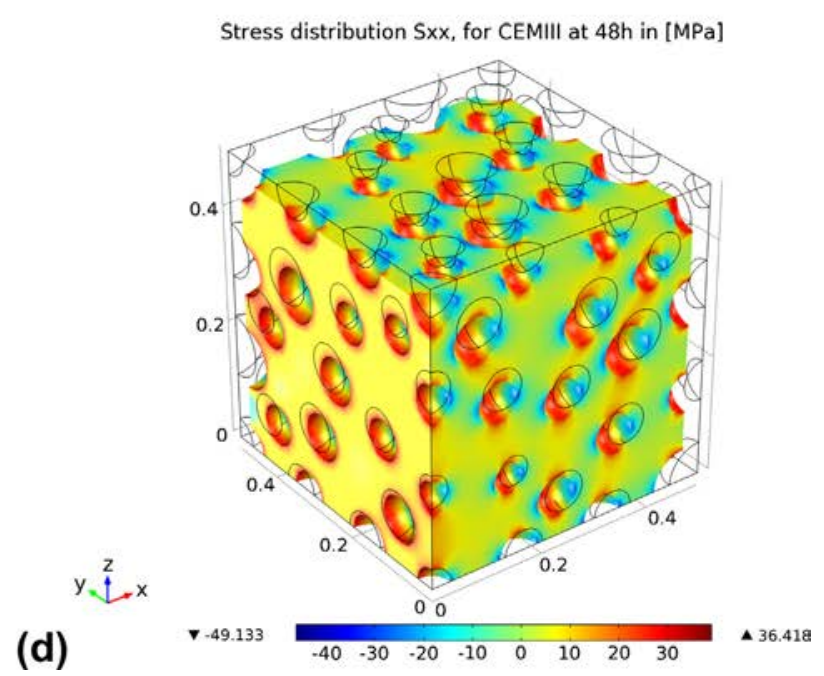

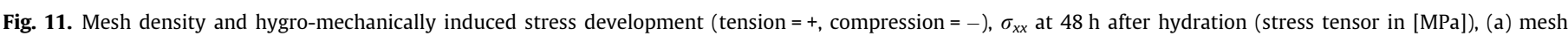
density including the grains and cement paste for our chosen numerical samples, (b) CEMI, (c) CEMII and (d) CEMIII.

using a Thermal Stress Testing Machine (TSTM) [2,90-92,7]. For a given water-to-binder ratio $\left(\frac{W}{B}\right)$, the presence of aggregates induces a dilution effect, which reduces the intensity of self-desiccation phenomena and therefore the magnitude of the average selfinduced stresses measured on a specimen section. Table 3 summarizes some experimental tensile stress values, mainly located between 0.8 and $3.2[\mathrm{MPa}]$ in accordance with the type of chosen concrete.

The experimental data on self-induced stresses obtained on cement pastes are seldom available in the open literature $[94,19,95,33]$. In these studies, the cement paste generally cracks earlier than concrete and the self-induced stresses rapidly became very low and vanish. Using a spherical stress sensor embedded in cement paste, Dela and Stang [94] and Bentz et al. [19] recorded high early-age self-generated compressive stresses. Dela and Stang reported values ranging between 15 and 20 [MPa] for a cement paste with $\frac{W}{C}=0.30$ and $20 \%$ of silica fume. Bentz et al. investigated the effect of cement fineness on the early-age crack sensitivity of cement pastes with $\frac{W}{C}=0.35$ and maintained at $30^{\circ} \mathrm{C}$. They observed that the compressive stresses for the finest cement rapidly decayed, at $50 \mathrm{~h}$, probably resulting from micro-cracks at the interface with the sensor. The coarser cements exhibited selfinduced compressive stress ranging between 4.5 and 7 [MPa] at the end of period of investigation (about $700 \mathrm{~h}$ of hydration). Using a mini-TSTM adapted to cement paste, Koenders et al. [95]) measured self-induced stresses between 2 and 5 [MPa] on Portland cement and blast furnace slag (BFS) cement pastes with a waterto-cement ratio of 0.35 and maintained in sealed conditions. Based on the latter investigation, the Portland cement paste cracks after $30 \mathrm{~h}$ of hydration at $3.5[\mathrm{MPa}]$ of self-induced stress, whereas the BFS ones do not crack during the period of investigation. This result is in agreement with the microscopical observations made on the cement pastes, which revealed a denser network of micro-cracks in the case of CEMI cement, compared to CEMII and CEMIII cements.

\section{Conclusions and outlooks}

The hygro-Cosserat numerical approach described in this paper is used to investigate the effects of cement paste composition on the development of self-induced stress caused by autogenous shrinkage in hydrating mortars. The above-mentioned numerical approach inherently undertakes the size effects, which are absent in the classical continuum theory [96]. The use of the Cosserat Size effect number sustains these effects in an explicit manner 
Stress distribution Sxx, for CEMI at $48 \mathrm{~h}$ in [MPa]

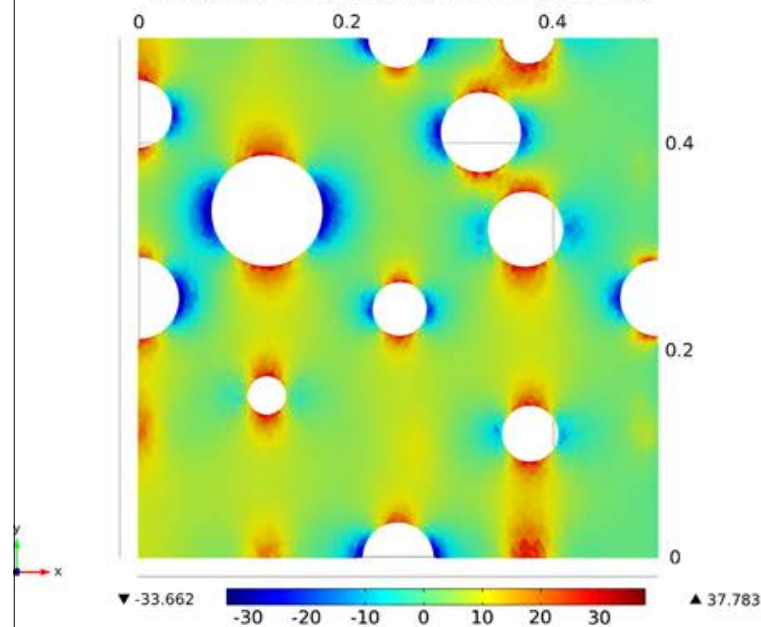

(a)

Stress distribution Sxx, for CEMII at $48 \mathrm{~h}$ in [MPa]

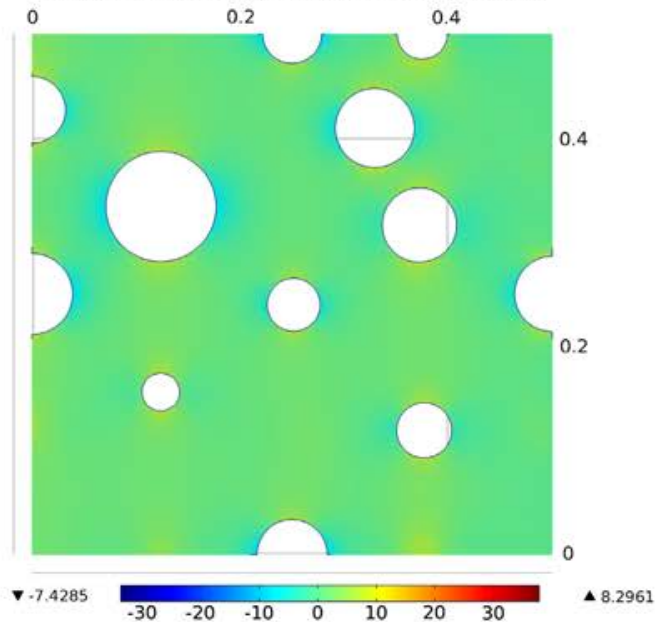

(c)

Stress distribution Sxx, for CEMIII at $48 \mathrm{~h}$ in [MPa]

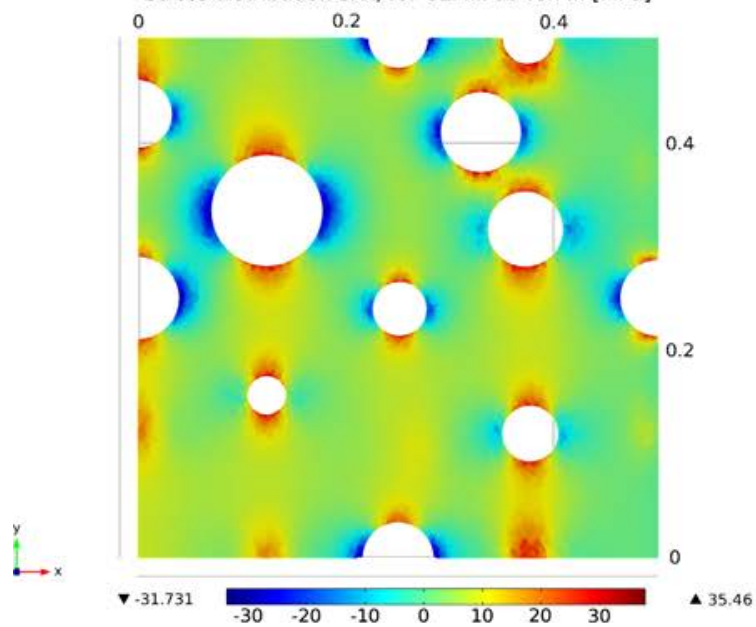

(e)

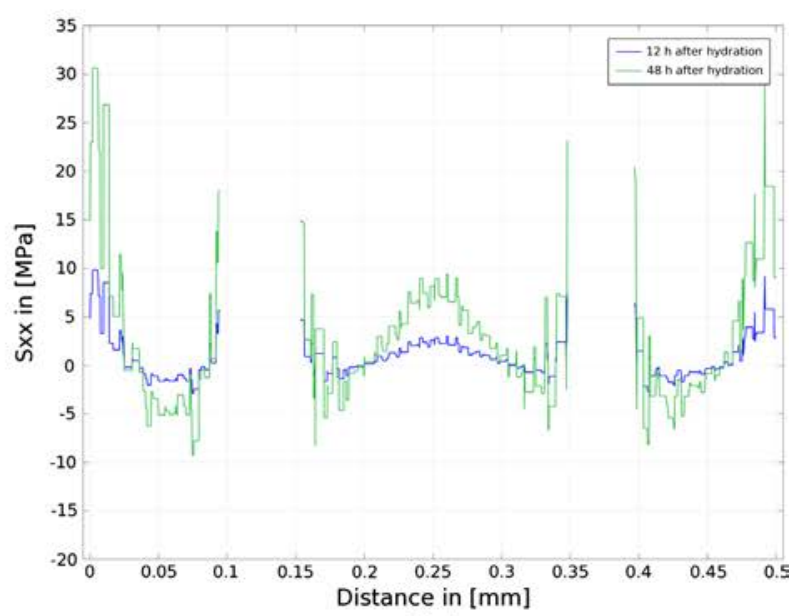

(b)

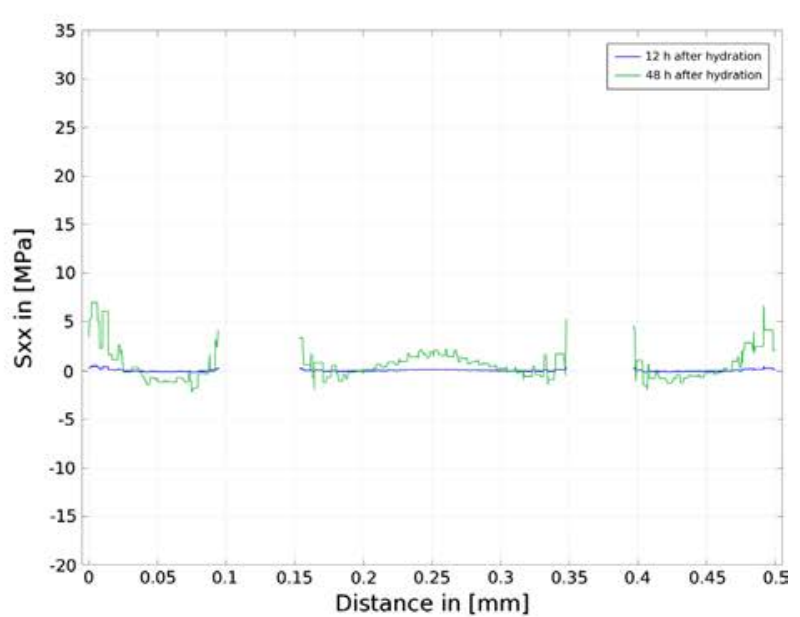

(d)

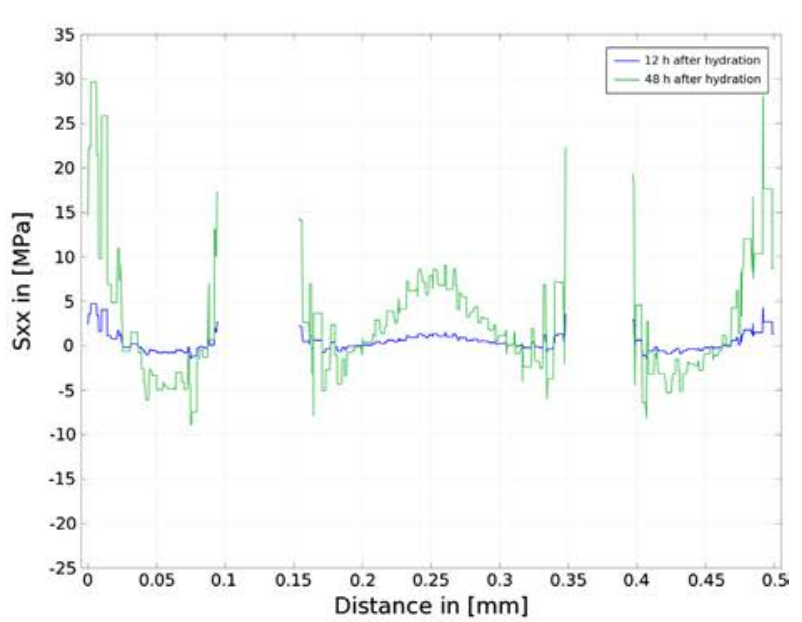

(f)

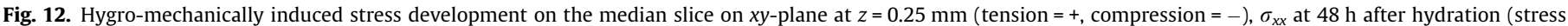

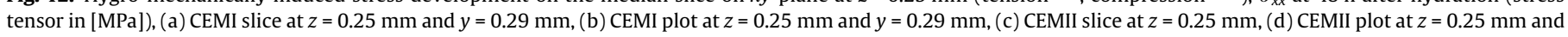
$y=0.29 \mathrm{~mm}$, (e) CEMIII slice at $z=0.25 \mathrm{~mm}$ and (f) CEMIII plot at $z=0.25 \mathrm{~mm}$ and $y=0.29 \mathrm{~mm}$. 
Table 3

Brief literature review of the self-induced stresses in early-age concretes (sealed conditions).

\begin{tabular}{|c|c|c|c|c|}
\hline References & Concrete type & Cement type & $\frac{W}{B}$ and $T$ & $\begin{array}{l}\text { Maximum intensity of tensile self-induced } \\
\text { stresses in isothermal curing }\end{array}$ \\
\hline Igarashi et al. [93] & $\begin{array}{l}\text { High strength concrete } \\
\text { mixtures }\end{array}$ & $\begin{array}{l}\text { Portland cement added or not with } 10 \% \\
\text { of silica fume }\end{array}$ & $\begin{array}{l}0.25 \\
0.33 \text { and } \\
30{ }^{\circ} \mathrm{C}\end{array}$ & $\begin{array}{l}\text { Between } 1.4 \text { and } 3.1 \mathrm{MPa} \text { at } 6 \text { days of hydration } \\
\text { (concrete with } \frac{W}{C}=0.33 \text { and silica fume cracked) }\end{array}$ \\
\hline Lura et al. [2] & $\begin{array}{l}\text { High performance concrete } \\
\text { (HPC) mixtures }\end{array}$ & $\begin{array}{l}\text { Portland cement (CEMI } 52.5 \text { R) and } \\
\text { blast-furnace slag cement (CEMII/B } \\
42.5 \text { LH HS) added with } 5 \% \text { of silica }\end{array}$ & $\begin{array}{l}0.35 \text { and } \\
20^{\circ} \mathrm{C} \\
( \pm 1.5 \mathrm{~K})\end{array}$ & $\begin{array}{l}\text { Between } 1.5 \text { and } 2.5 \text { MPa at } 6 \text { days of hydration } \\
\text { (no cracks observed) }\end{array}$ \\
\hline $\begin{array}{l}\text { Bjøntegaard and Sellevold } \\
\text { [91] }\end{array}$ & $\begin{array}{l}\text { Super high strength (SHS) } \\
\text { and normal high strength } \\
\text { (HS) concrete mixtures }\end{array}$ & $\begin{array}{l}\text { Portland cement (CEMI } 52.5 \text { LA) added } \\
\text { with } 20 \% \text { and } 5 \% \text { of silica fume }\end{array}$ & $\begin{array}{l}0.23 \\
0.40 \text { and } \\
20^{\circ} \mathrm{C}\end{array}$ & $\begin{array}{l}\text { (1) Crack of the SHS concrete at } 0.8 \text { MPa only a few } \\
\text { hours after setting, ( } 2 \text { ) crack of the HS concrete at } \\
\text { 3.2 MPa at } 4 \text { weeks of hydration }\end{array}$ \\
\hline Bisschop et al. [92] & $\begin{array}{l}\text { High strength concrete } \\
\text { (HSC) mixture }\end{array}$ & $\begin{array}{l}\text { Portland cement (CEMI } 52.5 \mathrm{R} \text { ) and } \\
\text { blast-furnace slag cement (CEMII/B } \\
42.5 \text { LH HS) }\end{array}$ & $\begin{array}{l}0.37 \text { and } \\
30{ }^{\circ} \mathrm{C}\end{array}$ & $\begin{array}{l}\text { Between } 2 \text { and } 2.7 \mathrm{MPa} \text { at } 6 \text { days of hydration } \\
\text { (two concrete cracked at } 48 \mathrm{~h} \text { and } 80 \mathrm{~h} \text { of } \\
\text { hydration) }\end{array}$ \\
\hline Sule and van Breugel [90] & $\begin{array}{l}\text { High strength concrete } \\
\text { (HSC) mixture }\end{array}$ & $\begin{array}{l}\text { Portland cement (CEMI } 52.5 \mathrm{R} \text { ) and } \\
\text { blast-furnace slag cement (CEMIII/B } \\
42.5 \text { LH HS) }\end{array}$ & $\begin{array}{l}0.33 \text { and } \\
20^{\circ} \mathrm{C} \\
( \pm 1.5 \mathrm{~K})\end{array}$ & $\begin{array}{l}\text { About } 2.6 \mathrm{MPa} \text { at } 6 \text { days of hydration (no cracks } \\
\text { observed) }\end{array}$ \\
\hline Darquennes et al. [7] & $\begin{array}{l}\text { High strength concrete } \\
\text { (HSC) mixtures }\end{array}$ & $\begin{array}{l}\text { Portland cement (CEMI } 52.5 \mathrm{~N} \text { ) and } \\
\text { blast-furnace slag cements (CEMIII/A } \\
\text { 42.5 LA and CEMIII/B } 42.5 \text { HSR LA) }\end{array}$ & $\begin{array}{l}0.45 \text { and } \\
20^{\circ} \mathrm{C} \\
( \pm 1.5 \mathrm{~K})\end{array}$ & $\begin{array}{l}\text { Three investigated concretes cracked at } 3 \mathrm{MPa} \text {, } \\
\text { reached at } 3.3,4.6 \text { and } 5.1 \text { days of hydration, } \\
\text { depending on the concrete mixtures }\end{array}$ \\
\hline
\end{tabular}

and it enables the size effect within $M_{T}-\log (C S)$ diagram. This diagram provides a smoothly motivated multi-scale modeling in the sense that for every CS value, one can obtain a distinct scale through the cement paste. Three cement pastes with a Portland cement (CEMI), a limestone cement (CEMII) and a slag cement (CEMIII) are considered. The free autogenous shrinkage and Young's modulus measurement have been performed on the cement pastes between 0 and $72 \mathrm{~h}$ of hydration are used as input data. The SEM observations are carried out at the interface between cement paste and aggregates and compared to the numerical outcomes.

Considering the same numerical conditions, i.e. pseudo-random geometry, mesh density and boundary conditions, the computation results shows that the stress development through the CEMII cement matrix is lower than CEMI and CEMIII. The scanning electron micrographs made at $48 \mathrm{~h}$ after hydration confirm that the CEMII is less sensitive to early-age cracking risk than the others. The numerical results reveal relatively close self-induced stress values for CEMI and CEMIII, while the microscopical observation of the interface matrix/aggregate clearly shows a denser network of micro-cracking for CEMI around the aggregates. This higher sensitivity of CEMI cement to early-age cracking, compared to CEMIII cement, is attributed to a lower stress relaxation capacity at early-age. This promising modeling approach can be improved by exploring the following further steps:

1. The effects of the exothermic chemical reactions and thermal deformations will be investigated through another multi-disciplinary problem (thermo-hygro-Cosserat elasticity). This issue should be involved to attain more realistic numerical modeling.

2 . The impact of the grains geometry (spherical grains or ellipsoidal grains) on the stress development within cement matrices.

3. The creep phenomenon should be also taken into account in the shrinkage micro-cracking analysis. This issue needs to be investigated very carefully due to the fact that macro-mechanically and the micro-mechanically viscoelastic behavior of cementbased materials must be well known and distinguished at meso-scale via the experiments.

\section{Acknowledgments}

The first author would like to thank Dr.-Ing. Ciprian Asavoie for his early contribution about the spherical packing algorithm from
Civil Engineering department of University of Işai in Romania and the European Union fellowship under BRAIN project. The second and fourth authors greatly appreciated the help of Dr. Annick Perronnet in performing the SEM observations.

\section{Appendix A. More about the Cosserat theory}

The main idea in the generalized continuum media is that each point in the material is small enough to be considered as a continuous medium (continuum mechanics compatibility issue including a conservative displacement vector assumptions) and it is large enough to sustain the micro-structural effects in the statistical manner [97]. As a matter of fact, contrary to the local approaches in fracture and fatigue failure using the classical continuum theory, e.g. [98-100], the Cosserat theory involves the built-in non-local aspects [101-103] using the characteristic length scale concept (see Fig. A.13).

\section{Appendix B. Hygro-Cosserat constitutive laws}

The hygro-Cosserat constitutive laws can be extracted via the following kinematical relations:

$\bar{\epsilon}^{T}=\nabla u-\bar{A}$

$\bar{k}=\nabla \phi$

and the total deformations measurement for Cosserat first stretch tensor and curvature tensor or wryness tensor in function of mechanical Cosserat first stretch tensors $\bar{\epsilon}^{\mathcal{M}}$ and mechanical curvature tensor or wryness tensor, $\bar{k}^{\mathcal{M}}$ :

$\bar{\epsilon}:=\bar{\epsilon}^{\mathcal{M}}+\bar{\epsilon}^{\mathcal{C}-\mathcal{H}} \quad$ where $\bar{\epsilon}^{\mathcal{C}-\mathcal{H}}:=\alpha^{\mathcal{C}-\mathcal{H}} \Delta \Pi \mathbf{1}$

$\bar{k}:=\bar{k}^{\mathcal{M}}$

The constitutive laws are defined in function of the mechanical deformation measurements as below:

$$
\begin{aligned}
& \sigma=\lambda \operatorname{tr}\left[\bar{\epsilon}^{\mathcal{M}}\right] \mathbf{1}+2 \mu \operatorname{sym} \bar{\epsilon}^{\mathcal{M}}+2 \mu_{c} \text { skew } \bar{\epsilon}^{\mathcal{M}} \\
& m=\alpha \operatorname{tr}\left[\bar{k}^{\mathcal{M}}\right] \mathbf{1}+\beta\left(\bar{k}^{\mathcal{M}}\right)^{T}+\gamma \bar{k}^{\mathcal{M}}
\end{aligned}
$$

By substitution of (B.1C) and (B.1d) into (B.2a) and (B.2b), one can simply obtain the following equations: 

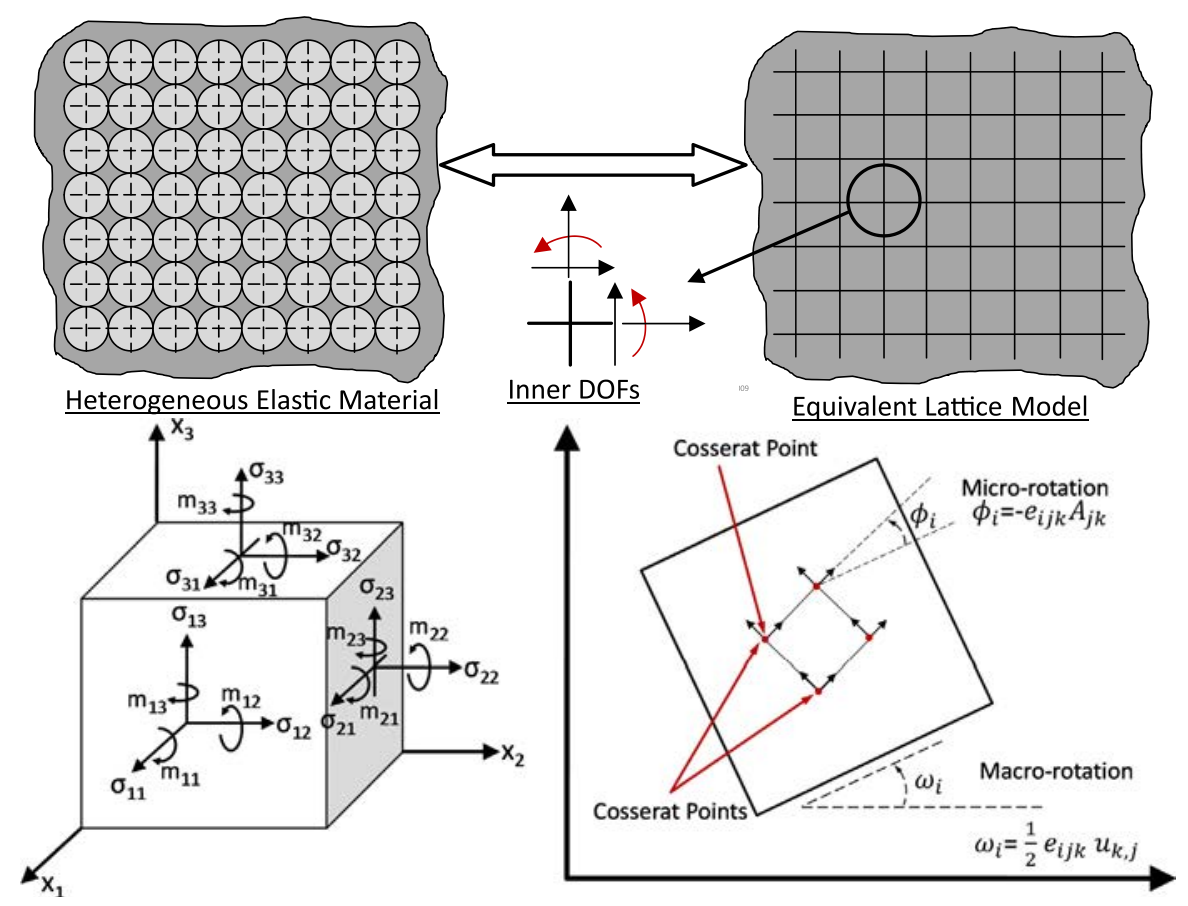

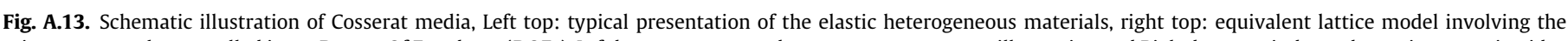

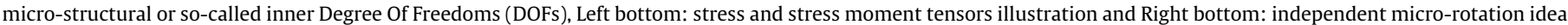
illustration including the macro-rotations in a typical Cosserat solid [104,105].

$$
\begin{aligned}
\sigma= & \lambda \operatorname{tr}\left[\bar{\epsilon}-\alpha^{\mathcal{C}-\mathcal{H}} \Delta \Pi \mathbf{1}\right] \mathbf{1}+2 \mu \operatorname{sym}\left(\bar{\epsilon}-\alpha^{\mathcal{C}-\mathcal{H}} \Delta \Pi \mathbf{1}\right) \\
& +2 \mu_{c} \operatorname{skew}\left(\bar{\epsilon}-\alpha^{\mathcal{C}-\mathcal{H}} \Delta \Pi \mathbf{1}\right) \\
m= & \alpha \operatorname{tr}[\bar{k}] \mathbf{1}+\beta \bar{k}^{T}+\gamma \bar{k} \text { or } m \\
= & \alpha \operatorname{tr}[\nabla \phi] \mathbf{1}+\beta \nabla \phi^{T}+\gamma \nabla \phi
\end{aligned}
$$

We can simplify further the above-written equations, i.e. (B.3a) and (B.3b) using the following relations:

$$
\begin{aligned}
& \operatorname{tr}\left[\bar{\epsilon}-\alpha^{\mathcal{C}-\mathcal{H}} \Delta \Pi \mathbf{1}\right]=\operatorname{tr}[\bar{\epsilon}]-\operatorname{tr}\left[\alpha^{\mathcal{C}-\mathcal{H}} \Delta \Pi \mathbf{1}\right]=\operatorname{tr}[\bar{\epsilon}]-3 \alpha^{\mathcal{C}-\mathcal{H}} \Delta \Pi \\
& \operatorname{sym}\left(\bar{\epsilon}-\alpha^{\mathcal{C}-\mathcal{H}} \Delta \Pi \mathbf{1}\right)=\operatorname{sym} \bar{\epsilon}-\operatorname{sym}\left(\alpha^{\mathcal{C}-\mathcal{H}} \Delta \Pi \mathbf{1}\right) \\
& \quad=\operatorname{sym} \bar{\epsilon}-\alpha^{\mathcal{C}-\mathcal{H}} \Delta \Pi \mathbf{1}
\end{aligned}
$$

$\operatorname{skew}\left(\bar{\epsilon}-\alpha^{\mathcal{C}-\mathcal{H}} \Delta \Pi \mathbf{1}\right)=\operatorname{skew} \bar{\epsilon}-\overbrace{\operatorname{skew}\left(\alpha^{\mathcal{C}-\mathcal{H}} \Delta \Pi \mathbf{1}\right)}^{\operatorname{skew}\left(\alpha^{\mathcal{C}-\mathcal{H}} \Delta \Pi \mathbf{1}\right)=0}=\operatorname{skew} \bar{\epsilon}$

The isotropic elastic Cosserat constitutive laws can be inferred including the hygric deformations as below:

$$
\begin{aligned}
\sigma & =\lambda \operatorname{tr}[\bar{\epsilon}] \mathbf{1}+2 \mu \operatorname{sym} \bar{\epsilon}+2 \mu_{c} \operatorname{skew} \bar{\epsilon}-\overbrace{\alpha^{\mathcal{C}-\mathcal{H}}(2 \mu+3 \lambda) \Delta \Pi \mathbf{1}}^{\chi:=\alpha^{\mathcal{C}-\mathcal{H}}(2 \mu+3 \lambda) \Delta \Pi \mathbf{1}} \text { or } \\
\sigma & =\lambda \operatorname{tr}[\bar{\epsilon}] \mathbf{1}+2 \mu \operatorname{sym} \bar{\epsilon}+2 \mu_{c} \operatorname{skew} \bar{\epsilon}-\chi \\
m & =\alpha \operatorname{tr}[\bar{k}] \mathbf{1}+\beta \bar{k}^{T}+\gamma \bar{k} \quad \text { or } m \\
& =\alpha \operatorname{tr}[\nabla \phi] \mathbf{1}+\beta \nabla \phi^{T}+\gamma \nabla \phi
\end{aligned}
$$

where $\chi \in \operatorname{ISO}(3) \subset \mathbb{R}^{3} \times \mathbb{R}^{3}$ is an isotropic second-rank tensor dealing with the bulk deformations induced via the chemo-mechanical effects throughout the porous solid subjected to the autogenous shrinkage phenomenon.

\section{Appendix C. Notations}

Let $\Omega \subset \mathbb{R}^{3}$ be a bounded domain with Lipschitz boundary. $\partial \Omega$ and let $\Gamma$ be a smooth subset of $\partial \Omega$ with non-vanishing 2-dimensional Hausdorff measure. For $a, b \in \mathbb{R}^{3}$ we let $a \cdot b$ denote the sca- lar product on $\mathbb{R}^{3}$ with associated vector norm $\|a\|_{R^{3}}^{2}=a \cdot b=a_{i} b_{i}$ for $i=1,2,3$ where $i \in \mathbb{N}$. We denote by $\mathbb{M}^{3 \times 3}$ or $\mathbb{R}^{3} \times \mathbb{R}^{3}$ the set of real $3 \times 3$ s order tensors, written with capital letters and sym denotes symmetric second orders tensors. The standard Euclidean scalar product on $\mathbb{M}^{3 \times 3}$ is given by $\langle X, Y\rangle_{\mathbb{M}^{3 \times 3}}=X: Y=\operatorname{tr} X Y^{T}=\operatorname{tr} X^{T} Y=X_{i j} Y_{i j}$ for $i, j=1,2,3$ where $i$, $j \in \mathbb{N}$, and thus the Frobenius tensor norm is $\|X\|^{2}=X: X=\langle X, X\rangle_{\mathbb{M}^{3 \times 3}}$. In the following we omit the index $\mathbb{R}^{3}, \mathbb{M}^{3 \times 3}$. The identity tensor on $\mathbb{M}^{3 \times 3}$ will be denoted by $\mathbf{1}$, so that $\operatorname{tr} X=\langle X, \mathbf{1}\rangle=X: \mathbf{1}=X_{i j} \delta_{i j}$ for $i, j=1,2,3$ where $i, j \in \mathbb{N}$. We denote the scalar product of permutation tensor (third-rank tensor) $e_{i j k}$ and a second-rank tensor $X$, so that $\mathbf{e} \cdot X=e_{i j k} X_{k l} \hat{e}_{i} \otimes \hat{e}_{j} \otimes \hat{e}_{l}$ and $\mathbf{e}: X=e_{i j k} X_{j k} \hat{e}_{i}$. The gradient of a vector can be denoted so that $\nabla a=a_{j, i} \hat{e}_{i} \otimes \hat{e}_{j}$ where $\nabla a \in \mathbb{M}^{3 \times 3}$ We set $\operatorname{sym}(X)=\frac{1}{2}\left(X^{T}+X\right)$ and skew $(X)=\frac{1}{2}\left(X-X^{T}\right)$ such that $X=\operatorname{sym}(X)+$ skew $(X)$ where $X \in \mathbb{M}^{3 \times 3}$. For $X \in \mathbb{M}^{3 \times 3}$ we set for the deviatoric part $\operatorname{dev} X=X-\frac{1}{3} \operatorname{tr} X \mathbf{1} \in \mathfrak{s l}(3)$ where $\mathfrak{s l}(3)$ is the Lie-algebra of traceless matrices. The set $\operatorname{Sym}(n)$ denotes all symmetric $n \times n$-matrices.

The Lie-algebra of SO (3): $=\left\{X \in \mathrm{GL}(3) \mid X^{T} X=\mathbf{1}\right.$, det $\left.X=1\right\}$ is given by the set $\mathfrak{s}(3):=\left\{X \in \mathbb{M}^{3 \times 3} \mid X^{T}=-X\right\}$ of all skew symmetric tensors. The canonical identification of $\mathfrak{s o}(3)$ and $\mathbb{R}^{3}$ is denoted by $\operatorname{axl} \bar{A} \in \mathbb{R}^{3}$ for $\bar{A} \in \mathfrak{s o}(3)$. Note that $(\operatorname{axl} \bar{A}) \times \xi=\bar{A}$. $\xi$ for all $\xi \in \mathbb{R}^{3}$, such that

$\operatorname{axl}\left(\begin{array}{ccc}0 & \alpha & \beta \\ -\alpha & 0 & \gamma \\ -\beta & -\gamma & 0\end{array}\right):=\left(\begin{array}{c}-\gamma \\ \beta \\ -\alpha\end{array}\right)$

$\bar{A}_{i j}=\sum_{k=1}^{3}-\epsilon_{i j k} \cdot \operatorname{axl} \bar{A}_{k}$,

$\|\bar{A}\|_{\mathbb{M}^{3 \times 3}}^{2}=2\|\operatorname{axl} \bar{A}\|_{\mathbb{R}^{3}}^{2}$

$\langle\bar{A}, \bar{B}\rangle_{\mathbb{M}^{3 \times 3}}=2\langle\operatorname{axl} \bar{A}, \operatorname{axl} \bar{B}\rangle_{\mathbb{R}^{3}}$ 
Under the Einstein's summation convention, the dual vector (axl) and dual tensor (anti) could be shown as below:

$$
\begin{aligned}
X & :=\operatorname{anti} x=-x_{i} e_{i j k} \hat{e}_{j} \otimes \hat{e}_{k}=-e_{i j k} x_{k} \hat{e}_{i} \otimes \hat{e}_{j} \\
& =-\mathbf{e} \cdot x \quad \text { where } x \in \mathbb{R}^{3} \text { and } X \in \mathbb{M}^{3 \times 3}
\end{aligned}
$$

$$
x:=\operatorname{axl} X=-\frac{1}{2} e_{i j k} X_{j k} \hat{e}_{i}=-\frac{1}{2} \mathbf{e}: X \quad \text { where } x \in \mathbb{R}^{3} \text { and } X \in \mathbb{M}^{3 \times 3}
$$

\section{References}

[1] Eppers Sören. Assessing the autogenous shrinkage cracking propensity of concrete by means of the restrained ring test. PhD thesis, Fakultät Bauingenieurwesen der Technischen Universität Dresden, Dresden; November 2010 [in English].

[2] Lura Pietro, van Breugel Klaas, Maruyama Ippei. Effect of curing temperature and type of cement on early-age shrinkage of high-performance concrete. Cem Concr Res 2001;31(12):1867-72.

[3] Jiang Zhengwu, Sun Zhenping, Wang Peiming. Autogenous relative humidity change and autogenous shrinkage of high-performance cement pastes. Cem Concr Res 2005;35(8):1539-45.

[4] Lee KM, Lee HK, Lee SH, Kim GY. Autogenous shrinkage of concrete containing granulated blast-furnace slag. Cem Concr Res 2006;36(7):1279-85.

[5] Hanehara S, Hirao H, Uchikawa H. Relationship between autogenous shrinkage and the microstructure and humidity changes at inner part of hardened cement pastes at early ages. In: International workshop on autogenous shrinkage of concrete Autoshrink '98, Hiroshima, Japan. London: E\&FN Spon; 1999. p. 89-100.

[6] Lura P. Autogenous deformation and internal curing of concrete. PhD thesis, TU Delft, Delft University of Technology, The Netherlands; April 2003 [in English].

[7] Darquennes Aveline, Staquet Stéphanie, Delplancke-Ogletree Marie-Paule, Espion Bernard. Effect of autogenous deformation on the cracking risk of slag cement concretes. Cem Concr Compos 2011;33(3):368-79.

[8] Tazawa E, Miyazawa S. Autogenous sbrinkage of concrete and its importance in concrete technology. In: Fifth international RILEM symposium in Barcelona, Great Britain. London: E and FN Spon; 1993. p. 159-68.

[9] Tazawa Ei ichi, Miyazawa Shingo, Kasai Tetsurou. Chemical shrinkage and autogenous shrinkage of hydrating cement Paste. Cem Concr Res $1995 ; 25(2): 288-92$

[10] Lim SN, Wee TH. Autogenous shrinkage of ground-granulated blast-furnace slag concrete. Mater J 2000;97(5):587-93. Document name: 97-M67.

[11] Bouasker M, Mounanga P, Khelidj A, Cou R. Free autogenous strain of early age cement paste: metrological development and critical analysis. Adv Cem Res 2008;20(2):75-84.

[12] Poppe Anne-Mieke, De Schutter Geert. Cement hydration in the presence of high filler contents. Cem Concr Res 2005;35(12):2290-9.

[13] Mounanga Pierre, Khokhar Muhammad, El Hachem Rana, Loukili Ahmed. Improvement of the early-age reactivity of fly ash and blast furnace slag cementitious systems using limestone filler. Mater Struct 2011;44(2):437-53.

[14] Itim Ahmed, Ezziane Karim, Kadri El-Hadj. Compressive strength and shrinkage of mortar containing various amounts of mineral additions. Constr Build Mater 2011;25(8):3603-9.

[15] Mounanga Pierre, Bouasker Marwen, Pertue Arnaud, Perronnet Annick, Khelidj Abdelhafid. Early-age autogenous cracking of cementitious matrices: physico-chemical analysis and micro/macro investigations. Mater Struct 2011;44(4):749-72.

[16] Geiker M. Studies of Portland cement hydration: measurements of chemical shrinkage and a systematic evaluation of hydration curves by means of the dispersion model. PhD thesis, Technical University of Denmark, Lyngby; 1983.

[17] Mounanga Pierre, Khelidj Abdelhafid, Loukili Ahmed, Baroghel-Bouny Véronique. Predicting $\mathrm{Ca}(\mathrm{OH}) 2$ content and chemical shrinkage of hydrating cement pastes using analytical approach. Cem Concr Res 2004;34(2):255-65.

[18] Bentz Dale P, Garboczi Edward J, Haecker Claus J, Jensen Ole M. Effects of cement particle size distribution on performance properties of Portland cement-based materials. Cem Concr Res 1999;29(10):1663-71.

[19] Bentz Dale P, Jensen Ole Mejlhede, Hansen Kurt Kielsgaard, Olesen John F, Stang Henrik, Haecker Claus-Jochen. Influence of cement particle-size distribution on early age autogenous strains and stresses in cement-based materials. J Am Ceram Soc 2001;84(1):129-35.

[20] Bentz Dale P, Sant Gaurav, Weiss Jason. Early-age properties of cement-based materials. I: Influence of cement fineness. J Mater Civil Eng 2008;20(7):502-8.

[21] Pickett Gerald. Effect of aggregate on shrinkage of concrete and a hypothesis concerning shrinkage. J Proc Am Concr Inst 1956;52(January 1):581-90.

[22] Hansen Torben C, Nielsen Knud EC. Influence of aggregate properties on concrete shrinkage. J Proc Am Concr Inst 1965;62(7):783-94. Document Name: JL62-48.

[23] Hobbs DW. Influence of aggregate restraint on the shrinkage of concrete. J Proc Am Concr Inst 1974;71(September 1):445-50.
[24] Hansen Will, Almudaiheem Jamal A. Ultimate drying shrinkage of concrete: influence of major parameters. Mater J Am Concr Inst 1978;84(3):217-23.

[25] Hua C, Ehrlacher A, Acker P. Analyses and models of the autogenous shrinkage of hardening cement paste II. Modelling at scale of hydrating grains. Cem Concr Res 1997;27(2):245-58.

[26] Xi Yunping, Jennings Hamlin. Shrinkage of cement paste and concrete modelled by a multiscale effective homogeneous theory. Mater Struct 1997;30(6):329-39.

[27] Pichler Christian, Lackner Roman, Mang Herbert A. A multiscale micromechanics model for the autogenous-shrinkage deformation of earlyage cement-based materials. Eng Fract Mech 2007;74(1-2):34-58. Fracture of Concrete Materials and Structures.

[28] Grondin F, Bouasker M, Mounanga P, Khelidj A, Perronnet A. Physicochemical deformations of solidifying cementitious systems: multiscale modelling. Mater Struct 2010;43(1):151-65.

[29] Hsu TTC. Mathematical analysis of shrinkage stresses in a model of hardened concrete. ACI J Proc 1963;60(3):371-90.

[30] Dela Birgitte Friis, Stang Henrik. Two-dimensional analysis of crack formation around aggregates in high-shrinkage cement paste. Eng Fract Mech 2000;65(23):149-64.

[31] Bisschop J, van Mier JGM. How to study drying shrinkage microcracking in cement-based materials using optical and scanning electron microscopy? Cem Concr Res 2002;32(2):279-87.

[32] Bisschop J, van Mier J. Effect of aggregates on drying shrinkage microcracking in cement-based composites. Mater Struct 2002;35(8):453-61.

[33] Lura Pietro, Couch Jon, Jensen Ole Mejlhede, Weiss Jason. Early-age acoustic emission measurements in hydrating cement paste: evidence for cavitation during solidification due to self-desiccation. Cem Concr Res 2009;39(10):861-7.

[34] Goltermann Per. Mechanical predictions on concrete deterioration. Part 1: Eigenstresses in concrete. ACI Mater J 1995;91(6):543-50. Document Name: 91-M54.

[35] Goltermann Per. Mechanical predictions of concrete deterioration; Part 2: Classification of crack patterns. ACI Mater J 1995;92(1):58-63. Document Name: 92-M07.

[36] Garboczi EJ. Stress, displacement, and expansive cracking around a single spherical aggregate under different expansive conditions. Cem Concr Res 1997;27(4):495-500.

[37] Moon JH, Couch J, Weiss J. Preliminary numerical assessment of microcracking caused by autogenous shrinkage in a heterogeneous system. In: Konsta-Gdoutos Maria S, editor. Measuring, monitoring and modeling concrete properties. Netherlands: Springer; 2006. p. 317-23.

[38] Schlangen E, Koenders EAB, van Breugel K. Influence of internal dilation on the fracture behaviour of multi-phase materialsll. Eng Fract Mech 2007;74(12):18-33. Fracture of Concrete Materials and Structures.

[39] Jeong Jena, Mounanga Pierre, Ramézani Hamidréza, Bouasker Marwen. A new multi-scale modeling approach based on hygro-Cosserat theory for selfinduced stress in hydrating cementitious mortars. Comput Mater Sci 2011;50(7):2063-74

[40] Jeong Jena, Neff Patrizio. Existence, uniqueness and stability in linear cossera elasticity for weakest curvature conditions, Math Mech Solids 2010;15(1):78-95. First published on September 17, 2008.

[41] Neff P, Jeong J. A new paradigm: the linear isotropic Cosserat model with conformally invariant curvature energy. ZAMM - J Appl Math Mech/Z Angew Math Mech 2009;89(2):107-22.

[42] Jeong J, Ramézani H, Münch I, Neff P. A numerical study for linear isotropic Cosserat elasticity with conformally invariant curvature. ZAMM - J Appl Math Mech/Z Angew Math Mech 2009;89(7):552-69.

[43] Neff P, Jeong J, Münch I, Ramézani H. Linear cosserat elasticity, conformal curvature and bounded stiffness. In: Maugin Gérard A, Metrikine Andrei V, editors. Mechanics of generalized continua. Advances in mechanics and mathematics, vol. 21. New York, Berlin: Springer; 2010. p. 55-63.

[44] Neff Patrizio, Jeong Jena, Fischle Andreas. Stable identification of linear isotropic Cosserat parameters: bounded stiffness in bending and torsion implies conformal invariance of curvature. Acta Mech 2010;211(3):237-49.

[45] Jeong Jena, Ramézani Hamidréza. Enhanced numerical study of infinitesimal non-linear Cosserat theory based on the grain size length scale assumption. Comput Methods Appl Mech Eng 2010;199(45-48):2892-902.

[46] Cosserat E, Cosserat F. Théorie des corps déformables. Librairie Scientifique A Hermann et Fils [Delphenich D Eng. Trans. 2007]. Paris; 1909.

[47] Cosserat E, Cosserat F. Note sur la Théorie de L'Action euclidienne. In: Appell P, editor. Traité de Mécanique Rationelle. vol. III. Paris: Gauthier-Villars; 1909. p. 557-629.

[48] Nunziato Jace W, Cowin Stephen C. A nonlinear theory of elastic materials with voids. Arch Ration Mech Anal 1979;72(2):175-201.

[49] Cowin Stephen C, Nunziato Jace W. Linear elastic materials with voids. J Elast $1983 ; 13(2): 125-47$.

[50] Ramézani Hamidréza, Steeb Holger, Jeong Jena. Analytical and numerical studies on penalized micro-dilatation (PMD) theory: macro-micro link concept. Eur J Mech - A/Solids 2012;34(0):130-48.

[51] Jeong Jena, Sardini Paul, Ramézani Hamidréza, Siitari-Kauppi Marja, Steeb Holger. Modeling of the induced chemo-mechanical stress through porous cement mortar subjected to co2: enhanced micro-dilatation theory and $14 \mathrm{c}-$ pmma method. Comput Mater Sci 2013;69(0):466-80.

[52] Mindlin RD. Micro-structure in linear elasticity. Arch Ration Mech Anal 1964;16(1):51-78. 
[53] Cemal Eringen A, Suhubi ES. Nonlinear theory of simple micro-elastic solids-I. Int J Eng Sci 1964;2(2):189-203.

[54] Cemal Eringen A. Theory of thermo-microstretch elastic solids. Int J Eng Sci 1990;28(12):1291-301.

[55] Eringen AC. Microcontinuum field theories. Microcontinuum field theories, vol. 2. Springer; 2001.

[56] Ramézani Hamidéza, El-Hraiech Amine, Jeong Jena, Benhamou ClaudeLaurent. Size effect method application for modeling of human cancellous bone using geometrically exact cosserat elasticity. Comput Methods Appl Mech Eng 2012;237-240:227-43.

[57] Ramézani Hamidréza, Jeong Jena, Feng Zhi-Qiang. On parallel simulation of a new linear Cosserat elasticity model with grid framework model assumptions. Appl Math Model 2011;35(10):4738-58.

[58] Neff Patrizio, Jeong Jena, Ramézani Hamidréza. Subgrid interaction and micro-randomness - Novel invariance requirements in infinitesimal gradient elasticity. Int J Solids Struct 2009;46(25-26):4261-76.

[59] Khoshbakht Mehran, Lin Mark W, Feickert Carl A. A finite element model for hygrothermal analysis of masonry walls with FRP reinforcement. Finite Elem Anal Des 2009;45(8-9):511-8.

[60] Lin Mark W, Berman Justin B, Khoshbakht Mehran, Feickert Carl A, Abatan Ayo O. Modeling of moisture migration in an FRP reinforced masonry structure. Build Environ 2006;41(5):646-56.

[61] Ramézani Hamidréza, Jeong Jena. Environmentally motivated modeling of hygro-thermally induced stresses in the layered limestone masonry structures: Physical motivation and numerical modeling. Acta Mech 2011;220(1):107-37.

[62] Wriggers P, Moftah SO. Mesoscale models for concrete: homogenisation and damage behaviour. Finite Elem Anal Des 2006;42(7):623-36. The Seventeenth Annual Robert J. Melosh Competition.

[63] Shahbeyk Sharif, Hosseini Morteza, Yaghoobi Mohammadreza. Mesoscale finite element prediction of concrete Failure. Comput Mater Sci 2011;50(7):1973-90.

[64] Jerier Jean-François, Imbault Didier, Donzé Frederic-Victor, Doremus Pierre. A geometric algorithm based on tetrahedral meshes to generate a dense polydisperse sphere packing. Granular Matter 2009;11(1):43-52.

[65] Lubachevsky Boris D, Stillinger Frank H. Geometric properties of random disk packings. J Statist Phys 1990;60(5):561-83.

[66] Kansal Anuraag R, Torquato Salvatore, Stillinger Frank H. Computer generation of dense polydisperse sphere packings. J Chem Phys 2002;117(18):8212-8.

[67] Jodrey WS, Tory EM. Computer simulation of close random packing of equal spheres. Phys Rev A 1985;32:2347-51.

[68] Kadushnikov Radii M, Nurkanov Eugenii Yu. Investigation of the density characteristics of three-dimensional stochastic packs of spherical particles using a computer model. Powder Metal Metal Ceram 2001;40(5):229-35.

[69] Mueller Gary E. Numerically packing spheres in cylinders. Powder Technol 2005;159(2):105-10.

[70] Jerier Jean-François, Richefeu Vincent, Imbault Didier, Donzé Fréderic-Victor. Packing spherical discrete elements for large scale simulations. Comput Methods Appl Mech Eng 2010;199(25-28):1668-76.

[71] Belheine N, Plassiard J-P, Donzé F-V, Darve F, Seridi A. Numerical simulation of drained triaxial test using 3D discrete element modeling. Comput Geotech 2009;36(1-2):320-31.

[72] Plassiard Jean-Patrick, Belheine Noura, Donzé Frédéric-Victor. A spherical discrete element model: calibration procedure and incremental response. Granular Matter 2009;11(5):293-306.

[73] Stroeven Piet, Stroeven Martijn. Dynamic computer simulation of concrete on different levels of the microstructure - Part 1. Image Anal Stereol $2003 ; 22: 1-10$.

[74] Stroeven Piet, Stroeven Martijn. Dynamic computer simulation of concrete on different levels of the microstructure - Part 2. Image Anal Stereol 2003;22(5):91-5.

[75] Frenning Göran. An efficient finite/discrete element procedure for simulating compression of 3D particle assemblies. Comput Methods Appl Mech Eng 2008;197(49-50):4266-72.

[76] Yen KZY, Chaki TK. A dynamic simulation of particle rearrangement in powder packings with realistic interactions. J Appl Phys 1992;71(7):3164-73.

[77] Richefeu V, El Youssoufi MS, Peyroux R, Radjäi F. A model of capillary cohesion for numerical simulations of 3D polydisperse granular media. Int J Numer Anal Methods Geomech 2008;32(11):1365-83.

[78] Asavoaie Ciprian. On the spherical packing of the grains through the cement paste matrix: state-of-the-art algorithms; January 2011 [in Romanian].

[79] Bouasker Marwen. Étude numérique et expérimentale du retrait endogène au très jeune âge des pâtes de ciment avec et sans inclusions. PhD thesis, University of Nantes; November 2007 [in French].

[80] Spinner S, Tefft WE. A method for determining mechanical resonance frequencies and for calculating elastic moduli from these frequencies. In: Proceedings ASTM, vol. 61; 1961. p. 1221-39.
[81] Justnes H, Van Gemert A, Verboven F, Sellevold EJ. Total and external chemical shrinkage of low w/c-ratio cement pastes. Adv Cem Res 1996;31(8):121-6.

[82] Lura P, Jensen OM, van Breugel K. Autogenous deformation and rh change in portland and blast furnace slag cement pastes. In: Proceedings of selfdisccation and its importence in concrete technology. Lund (Sweden): Persson B and Fagerlund G; 2002. p. 127-38.

[83] Boumiz A, Vernet C, Cohen Tenoudji F. Mechanical properties of cement pastes and mortars at early ages: evolution with time and degree of hydration. Adv Cem Mater 1996;3(3-4):94-106.

[84] Sant G, Lura P, Weiss J. A discussion of analysis approaches for determining 'time-zero' from chemical shrinkage and autogenous strain measurements in cement paste. In: International RILEM conference on volume changes of hardening concrete: testing and mitigation, 20-23 August, 2006. Lyngby, Denmark: Technical University of Denmark; 2006.

[85] Chang-Wen Miao, Qian Tian, Wei Sun, Jia-ping Liu. Water consumption of the early-age paste and the determination of time-zero of self-desiccation shrinkage. Cem Concr Res 2007;37(11):1496-501.

[86] Sant G, Dehadrai M, Bentz D, Lura P, Ferraris CF, Bullard JW, et al. Detecting the fluid-to-solid transition in cement pastes. Concr Int 2009;31(6):53-8. Document Name: CI3106Sant.

[87] Münch I, Wagner W, Neff P. Constitutive modeling and FEM for a nonlinear Cosserat continuum. PAMM 2006;6(1):499-500.

[88] Lura Pietro, Jensen Ole, Weiss Jason. Cracking in cement paste induced by autogenous shrinkage. Mater Struct 2009;42(8):1089-99.

[89] Pane Ivindra, Hansen Will. Investigation on key properties controlling earlyage stress development of blended cement concrete. Cem Concr Res 2008;38(11):1325-35.

[90] Sule M, van Breugel K. Experimental investigation of cracking behavior of reinforced high strength concrete. In: Kovler $\mathrm{K}$, Bentur A, editors. International RILEM conference on early age cracking in cementitious systems. RILEM Publications SARL; 2003. p. 327-34.

[91] Bjøntegaard Ø, Sellevold EJ. Crack sensitivity at early age for high strength and super high strength concrete. In: Kovler K, Bentur A, editors. International RILEM conference on early age cracking in cementitious systems. RILEM Publications SARL; 2003. p. 311-8.

[92] Bisschop J, Lura P, van Mier J. Shrinkage microcracking in cement-based materials with low water-cement ratio. In: Kovler K, Bentur A, editors. International RILEM conference on early age cracking in cementitious systems. RILEM Publications SARL; 2003. p. 79-88.

[93] Igarashi Shin ichi, Bentur Arnon, Kovler Konstantin. Autogenous shrinkage and induced restraining stresses in high-strength concretes. Cem Concr Res 2000;30(11):1701-7.

[94] Dela B, Stang H. Eigenstresses in concrete due to autogenous shrinkage. Technical report, Lund Institute of Technology, Div. Building Materials; 1997 (Report TVBM-3075, p. 46-51).

[95] Koenders EAB, Schlangen E, Leegwater G. A mini-TSTM for measuring paste deformations at early ages. In: International RILEM conference on volume changes of hardening concrete: testing and mitigation. Lyngby, Denmark: Technical University of Denmark; 2006.

[96] Neff Patrizio, Forest Samuel. A geometrically exact micromorphic model for elastic metallic foams accounting for affine microstructure. Modelling, existence of minimizers, identification of moduli and computational results. J Elast 2007;87(2):239-76.

[97] Neff Patrizio, Jeong Jena, Münch Ingo, Ramézani Hamid. Mean field modeling of isotropic random Cauchy elasticity versus microstretch elasticity. Z Angew Math Phys (ZAMP) 2009;60(3):479-97.

[98] Pluvinage G. Fracture and fatigue emanating from stress concentrators. Kluwer Academic Publishers; 2003.

[99] Adib H, Pluvinage G. Theoretical and numerical aspects of the volumetric approach for fatigue life prediction in notched components. Int J Fatigue 2003;25(1):67-76.

[100] Adib-Ramezani H, Jeong J. Advanced volumetric method for fatigue life prediction using stress gradient effects at notch roots. Comput Mater Sci 2007;39(3):649-63.

[101] Kroner E. Elasticity theory of materials with long range cohesive forces. Int J Solids Struct 1967;3(5):731-42.

[102] Cemal Eringen A. Nonlocal polar elastic continua. Int J Eng Sci $1972 ; 10(1): 1-16$.

[103] Pijaudier-Cabot G, Bazant ZP. Non local damage theory. J Eng Mech, ASCE 1987;113(10):1512-33.

[104] Sadd Martin Howard. Elasticity: theory, applications, and numerics. Referex engineering. Elsevier Butterworth Heinemann; 2005.

[105] Jeong J, Adib-Ramezani H, Al-Mukhtar M. Numerical simulation of elastic linear micropolar media based on the pore space length scale assumption. Strength Mater 2008;40(4):425-38. 